\title{
Alterations in Lipid Levels of Mitochondrial Membranes Induced by Amyloid- $\beta$ : A Protective Role of Melatonin
}

\author{
Sergio A. Rosales-Corral,, ${ }^{1,}$ Gabriela Lopez-Armas, ${ }^{2}$ Jose Cruz-Ramos, ${ }^{2}$ Valery G. Melnikov, ${ }^{3}$ \\ Dun-Xian Tan, ${ }^{1}$ Lucien C. Manchester, ${ }^{1}$ Ruben Munoz, ${ }^{4}$ and Russel J. Reiter ${ }^{1}$
}

${ }^{1}$ Department of Cellular and Structural Biology, University of Texas Health Science Center at San Antonio, 7703 Floyd Curl Dr., San Antonio, TX 78229, USA

${ }^{2}$ División Neurociencias, Centro de investigación Biomédica de Occidente, Instituto Mexicano del Seguro Social, Sierra Mojada 800 Col. Independencia, 44340 Guadalajara, JAL, Mexico

${ }^{3}$ University Center for Biomedical Research Center, University of Colima, Colima, COL, Mexico

${ }^{4}$ Departamento de Química, Centro de Ciencias Exactas e Ingenieria (CUCEI), Universidad de Guadalajara, Blvd. Marcelino García Barragan 1421, 44430 Guadalajara, JAL, Mexico

Correspondence should be addressed to Sergio A. Rosales-Corral, rosalescorra@uthscsa.edu

Received 19 December 2011; Accepted 9 February 2012

Academic Editor: K. S. Jagannatha Rao

Copyright ( 92012 Sergio A. Rosales-Corral et al. This is an open access article distributed under the Creative Commons Attribution License, which permits unrestricted use, distribution, and reproduction in any medium, provided the original work is properly cited.

\begin{abstract}
Alzheimer pathogenesis involves mitochondrial dysfunction, which is closely related to amyloid- $\beta$ (A $\beta$ ) generation, abnormal tau phosphorylation, oxidative stress, and apoptosis. Alterations in membranal components, including cholesterol and fatty acids, their characteristics, disposition, and distribution along the membranes, have been studied as evidence of cell membrane alterations in $\mathrm{AD}$ brain. The majority of these studies have been focused on the cytoplasmic membrane; meanwhile the mitochondrial membranes have been less explored. In this work, we studied lipids and mitochondrial membranes in vivo, following intracerebral injection of fibrillar amyloid- $\beta(\mathrm{A} \beta)$. The purpose was to determine how $\mathrm{A} \beta$ may be responsible for beginning of a vicious cycle where oxidative stress and alterations in cholesterol, lipids and fatty acids, feed back on each other to cause mitochondrial dysfunction. We observed changes in mitochondrial membrane lipids, and fatty acids, following intracerebral injection of fibrillar $\mathrm{A} \beta$ in aged Wistar rats. Melatonin, a well-known antioxidant and neuroimmunomodulator indoleamine, reversed some of these alterations and protected mitochondrial membranes from obvious damage. Additionally, melatonin increased the levels of linolenic and $\mathrm{n}-3$ eicosapentaenoic acid, in the same site where amyloid $\beta$ was injected, favoring an endogenous anti-inflammatory pathway.
\end{abstract}

\section{Introduction}

We hypothesized that due to its amphipathic nature [1], its physicochemical functions [2] and aided by the induced oxidative stress $[3,4], \mathrm{A} \beta$ paves its own pathway from the extracellular space to the mitochondria where it disrupts membrane fluidity and causes energetic dysfunction. This mechanism of membrane permeabilization induced by $\mathrm{A} \beta$ and its own internalization might be the major cause of mitochondrial dysfunction.

Following injection of $\mathrm{A} \beta_{1-42}$ into the hippocampus of healthy Wistar 6-month-old rats, we reported deposits of this peptide fragment forming plaques in the extracellular space. Thereafter $\mathrm{A} \beta$ was observed in cytoplasmic membranes, especially those of axons, where it accumulated in one or two poles of the axons giving the appearance of onion bulbs, as observed in demyelinating pathologies. Demyelination is also a feature of Alzheimer's disease (AD) $[5,6]$. It is noteworthy that the animals used in the experiments had no other condition or genetic predisposition to form plaques or other $\mathrm{AD}$ features. $\mathrm{A} \beta$ peptide then appeared in the cytoplasm, and finally in mitochondrial membranes, where its presence was associated with mitochondrial dysfunction. The question remaining is what alterations $\mathrm{A} \beta$ produce in the 
lipid composition of mitochondrial membranes, particularly in those fatty acids and phospholipids previously related to the $A \beta$ pathogeny. Moreover, if $A \beta$-induced oxidative stress plays a key role in damaging lipids in cell membranes, what is the potential role of the antioxidant melatonin when this process affects mitochondrial membranes?

Lipid and fatty acid changes have been studied primarily in plasma membranes or in synaptosomes prepared from $\mathrm{AD}$ postmortem brains; those changes have been associated with aging, $\mathrm{A} \beta$ deposits, dementia, and even with mild cognitive impairment. Other results have been obtained using purified synaptosomal plasma membranes from transgenic mouse brain. To our knowledge, no studies have focused on mitochondrial membranes in response to in vivo extracellular deposits of fibrillar $A \beta$. This approach has relevance to the aforementioned hypothesis and our previous results.

The lipid sensing and lipid-regulated proteolysis is a wellcharacterized phenomenon. This involves the processing of the sterol regulatory element binding proteins (SREBPs), as the best known example [7]. Likewise, saturated fatty acids are related both to amyloidogenesis and to tau hyperphosphorylation. Palmitic acid (PA) is related to the $\beta$-site amyloid precursor protein (APP) cleaving enzyme (BACE1) upregulation and amyloidogenic processing of APP in primary rat cortical neurons [8]. Also, cortical neurons growing in conditioned media from astrocytes treated with palmitic acid and the unsaturated oleic acid expressed hyperphosphorylation of the tau protein. This was later found to be an oxidative-related phenomenon since the addition of the antioxidant $\mathrm{N}$-acetyl cysteine reduced hyperphosphorylation of tau [9]. Changes or reaccommodations of fatty acids within the lipidic structures are continuous, and this may represent oxidative stress-induced remodeling [10]. However, an $\mathrm{AD}$-specific or an $\mathrm{A} \beta$-induced specific change does not exist. Nonetheless, it is also known that unsaturated fatty acids, specifically oleic and linoleic acids, may stimulate presenilin-1 levels and $\gamma$-secretase activity, which participate in the generation of $A \beta$ [11].

The relationship between oxidative stress, peroxidation of membrane lipids, and neurodegeneration has been primarily explored in postmortem studies, where a significant decline in polyunsaturated fatty acids (PUFAs), especially arachidonic and docosahexenoic acids, has been found [12]. These changes are directly related to the augmentation in 4hydroxynonenal, a toxic by-product of the peroxidation of membrane PUFAs, especially arachidonic acid (AA) [13]. In fact, $A \beta$ may induce the phospholipase $A 2$, responsible for AA release from cytoplasmic membranes [14]. The observed drop in docosahexaenoic acid (DHA), on the other hand, is correlated with the dietary intake of DHA which may reduce the amyloid burden [15] by stimulating the nonamyloidogenic processing of APP [16]. Fatty acids modulate the production and activity of a variety of neurotransmitters and the alterations of fatty acids in the diet of rodents have been demonstrated to result in changes in the ability of the animals to learn or retain new information $[17,18]$. The ratio between unsaturated and saturated FA (U/S) expresses the degree of unsaturation being linked to less membrane fluidity as an adaptative phenomenon. Changes in the ratio of these fatty acids have been thought to be involved in a variety of diseases including cancer, diabetes, and neurologic diseases. The overproduction of $A \beta$ leads to a decline in $\Delta$ 9 desaturase activity with an alteration in membrane fatty acids This results in altered membrane mobility leading to a decline in neurotransmitter activity and a decreased release of acetylcholine [19].

It has been demonstrated that $\mathrm{A} \beta$ peptides interact with anionic lipids which leads to a significant alteration in the properties of the bilayer itself. Phosphate groups in anionic lipids and aliphatic aminoacids (Val-Val-Ile-Ala) at the Cterminal end of $\mathrm{A} \beta$ mediate that interaction while oxidative stress induces a significant rise in anionic phosphatidylserine (Ptd-Ser). Membrane disruption induced by $\mathrm{A} \beta$-peptide is mediated through perturbations of the lipid order caused by interaction of peptides with head groups and/or formation of micelles [20]. Reciprocally, when incubated with PtdSer, $A \beta$ undergoes transformation from a random coil to a $\beta$-structure [21]. Furthermore, there seems to be a cell selective neurotoxicity due to $\mathrm{A} \beta$ determined by surface PtdSer, apart from the levels of ATP [22]; this also relates to our hypothesis. Thus, the capacity of cells to bind $\mathrm{A} \beta$ seems to be associated with cells with expressed measurable PtdSer on the membrane surface, and this feature is correlated with apoptotic signaling. It should be noted that Ptd-Ser is normally found on the inner face of the surface membrane of healthy cells. In the early stage of apoptosis, however, or under specific stimulation, such as $\mathrm{Ca}^{2+}$ influx, a hallmark in the mitochondrial pathogenic mechanisms possibly involved in $\mathrm{AD}[23,24]$, Ptd-Ser can translocate to the outer leaflets of the plasma membrane and be exposed to the extracellular space. Thus, Ptd-Ser becomes a surface receptor site for $\mathrm{A} \beta$ binding, in such a manner that annexin or apolipoprotein E2, proteins with the ability to interact with Ptd-Ser, may protect neurons from $A \beta$ neurotoxicity [25]. Since Ptd-Ser is an anionic phospholipid, it may produce an acidic local environment, which is optimal for aggregation of the $A \beta$ peptide [26].

Phosphatidylcholine (PtdChol) is a major constituent of cell membranes, commonly found in the outer leaflet, and it is a particular target for $\mathrm{A} \beta$. For example, evaluated in zwitterionic bilayers based on PtdChol membranes, $A \beta$ associates with lipid heads, and when fused into a zwitterionic planar bilayer, it is rapidly transformed from helical- to $\beta$-structure and exhibits a channel-like behavior [27]. In this manner, $A \beta$ disturbs intracellular calcium homeostasis because it renders lipid bilayers permeable to ions.

Changes in packing and orientation of phospholipids in membranes is a phenomenon promoted by cholesterol, which modulates the membrane binding of amyloidogenic proteins $[28,29]$. It has been documented that cholesterol increases the binding of $\mathrm{A} \beta$ to lipid membranes [30, 31]. The concentration of cholesterol in the membranes has been related to the extent and depth of insertion of $\mathrm{A} \beta$ into the membrane [32]. However, a computational study using PtdChol and PtdChol/cholesterol bilayers, which mimic the cholesterol depleted and enriched lipid domains of neuronal membranes, revealed a protective role of cholesterol in preventing both $\mathrm{A} \beta$-induced 
membrane disruption and membrane surface-induced $\beta$ sheet formation [33]. Nonetheless, by electron paramagnetic resonance spectroscopy, it has been demonstrated how, driven by hydrophobic interactions, $A \beta$ is inserted into bilayers, between the outer part of the hydrophobic core and the external hydrophilic layer. This causes displacement of cholesterol towards the more external part of the membrane where the crowding of cholesterol in turn causes membrane rigidity in this region of the bilayer [34]. This membrane rigidity has been demonstrated in mitochondria obtained from postmortem $\mathrm{AD}$ brain [35]; importantly, alterations in mitochondrial membrane fluidity are primarily related to lipid peroxidation [36], which, again, emphasizes the importance of oxidative stress.

Since oxidative stress is a major event in $\mathrm{AD}$ progression and is especially related to membrane dysfunction, mitochondrial failure, and apoptosis, the antioxidant melatonin has proven useful in delaying the progression of damage in $\mathrm{AD}$ [24]. We have demonstrated in in vivo experiments after the injection of $A \beta$ directly into the hippocampus that orally administered melatonin is more effective in reducing oxidative stress than are vitamins C and E [4]. The effect of melatonin has been shown to be especially protective for PUFAs during nonenzymatic lipid peroxidation [37], as observed in transgenic mouse model of $\mathrm{AD}$ [38]. Melatonin also may preserve arachidonic and docosapentaenoic acids as observed during ascorbate- $\mathrm{Fe}^{++}$peroxidation in rat testicular microsomes and mitochondria [39].

The current work is based in those fatty acids or lipids previously reported to be involved in $\mathrm{A} \beta$-lipid interactions and the protective effect of melatonin on $\mathrm{A} \beta$-induced membrane disruption; this latter process is mediated through perturbations of the lipid order caused by an interaction of peptides with head groups and/or formation of micelles [20]. Our results correspond exclusively at the region of the hippocampus where the $\mathrm{A} \beta$ was injected.

\section{Materials and Methods}

2.1. Animals and Experimental Design. Surgical and animal care procedures were performed with strict adherence to the guide for the Care and Use of Laboratory Animals (National Institutes of Health, publication number 86-23, Bethesda, $\mathrm{MD}$, USA). All protocols and procedures were approved by the institution's Animal Care and Use Committee. Male Wistar rats (250-280 grams; 3-month-old) were housed in pairs in a colony room on a 12:12 dark/light cycle with lights off at 20:00 h; food and water were provided ad libitum. The rats were divided $(n=5)$ into the following groups: (1) PBSinjected rats, (2) fibrillar $\mathrm{A} \beta_{1-42}$-injected rats (fA $\beta$ ), and (3) $\mathrm{H}_{2} \mathrm{O}_{2}(200 \mu \mathrm{M})$ intracerebrally injected rats. Two additional groups, $\mathrm{fA} \beta+\mathrm{Mel}$ and $\mathrm{H}_{2} \mathrm{O}_{2}+\mathrm{Mel}$, were included. In this case, the fA $\beta$ or $\mathrm{H}_{2} \mathrm{O}_{2}$-intracerebrally injected animals received antioxidant treatment with melatonin (Sigma, St. Louis, MO, USA) dissolved in the drinking water to yield an estimated daily dose of $20 \mathrm{mg} / \mathrm{kg} / \mathrm{day}$. IPBS was used as control instead of $A \beta$ peptides since even nontoxic $A \beta$ derivatives, such as the scrambled $\mathrm{A} \beta$ usually employed as control in in vivo models, may themselves produce free radicals $[40,41] . \mathrm{H}_{2} \mathrm{O}_{2}$ was chosen as a positive control because of its close relationship with $\mathrm{A} \beta$ pathogeny [42]. $\mathrm{H}_{2} \mathrm{O}_{2}$ is considered its principal mediator [43] and secondary messenger of death signals [44]. Additionally, $\mathrm{H}_{2} \mathrm{O}_{2}$ accumulates in mitochondria long before the appearance of $\mathrm{A} \beta$ plaques in the extracellular space as evaluated in Tg2576 mice [45].

2.2. Brain Coordinates for Hippocampal Injections. Hippocampal injections of $\mathrm{A} \beta_{1-42}(2 \mu \mathrm{L}$ at a final concentration of $1 \mathrm{mM}$ ) were performed as previously described $[4,46,47]$. Lyophilized synthetic $\mathrm{A} \beta_{1-42}$ (Sigma, St. Louis, MO, USA) peptide was solubilized $\left(10^{-4} \mathrm{M}\right)$ in filtered PBS; it was then allowed to incubate with continuous agitation (Teflon stir bar at $800 \mathrm{rpm})$ at $23^{\circ} \mathrm{C}$ for $36 \mathrm{~h}$ in order to form fibrillar aggregates. Rats, anaesthetized with chloral hydrate $(350 \mathrm{mg} / \mathrm{kg}$, i.p.), were placed in a stereotaxic instrument for intracerebral injection over a $5 \mathrm{~min}$ period (coordinates: anterior-posterior $=-3.8 \mathrm{~mm}$, medial-lateral $=2.0 \mathrm{~mm}$, dorsal-ventral $=2.6 \mathrm{~mm}$ from bregma; this corresponds to the CA1 region as determined by the atlas of Paxinos and Watson [48] as a guide) using $5 \mu \mathrm{L}$ Hamilton microsyringe coupled to a 30-gauge needle through flexible tubing. The needle was left in place for $5 \mathrm{~min}$ after the injection. The same coordinates were used for experiments with $\mathrm{H}_{2} \mathrm{O}_{2}$. 36 hours after the injections, rats were deeply anesthetized and transcardially perfused with $200 \mathrm{~mL}$ of PBS. Those animals used for immunohistochemical procedures were additionally perfused with $4 \%$ paraformaldehyde. The rats were sacrificed by decapitation and the brain was removed immediately, placed in cold PBS, and a piece of tissue (164$180 \mathrm{mg}$ ), including the lesioned area, was taken with a punch (diameter $10 \mathrm{~mm}$ ), at the base of the needle tract. This piece included the hippocampus and adjacent cortical areas.

2.3. Immunoelectron Microscopy. For immunoelectron microscopy, the hippocampal tissue samples were fixed in $4 \%$ paraformaldehyde for 24 hours and immersed in $2.3 \mathrm{M}$ sucrose solution for 24 hours. Thereafter, small blocks were cut and postfixed in osmium tetroxide (2\% in PB $0.2 \mathrm{M})$ for 45 minutes and then embedded for 48 hours in Embed 812 (Electron microscopy Sciences). Ultrathin sections of 70-90 nm were cut with an ultramicrotome (Reichert Om3) and mounted on nickel grids and then incubated for 2 hours in $5 \%$ BSA and $0.1 \%$ fish gelatin. For the immunolabeling experiment, the mounted sections were then incubated for 24 hours at $4^{\circ} \mathrm{C}$ with the primary polyclonal antibody Anti- $\beta$ A (Anti- $\beta$ A42, from Santa Cruz) at a dilution 1:1000, then washed four times with PBS $0.1 \mathrm{M}$ and $0.1 \%$ tween-20, and further incubated for 3 hours at room temperature with a $6 \mathrm{nM}$ gold-conjugated secondary goat anti-rabbit antibody (Jackson Immunoresearch Laboratories) at a dilution of $1: 500$. After four washes with PBS, sections were counterstained with uranyl acetate (2\%) for 15 minutes and lead citrate for 5 minutes and examined in a Zeiss EM 906 transmission electron microscope (Oberkochen, Germany). 
2.4. In Vivo Analysis of Mitochondrial Free Radicals. Analysis of mitochondrial free radical generation-Mitotracker red CM-H2XRos (Molecular Probes), a rosamine derivative used to detect mitochondrial free radicals, was diluted in DMSO to form a $1 \mathrm{mM}$ stock solution. $100 \mu \mathrm{L}$ of that solution was diluted in $5 \mathrm{~mL}$ of physiological saline and stored sterile at $4^{\circ} \mathrm{C}$ as a working solution. Applied at a dose of $0.030 \mu \mathrm{g} / \mathrm{kg}$, $\mathrm{CM}-\mathrm{H} 2 \mathrm{XR}$ os did not affect the functional properties of mitochondria after loading, since neither the respiratory output nor cell viability was significantly changed, as evaluated in a separate study (data not shown). Two hours following the intraperitoneal injection of CM-H2XRos, animals were perfused transcardially with PBS followed by $4 \%$ paraformaldehyde. The brain was immediately removed and immersed in the fixative for $8-10 \mathrm{~h}$. Following a brief washing in PBS, brain slices were cut into $25-30 \mu \mathrm{m}$ thick sections, including the area of interest, with the vibratome and incubated freefloating in Mito Tracker Green (Molecular Probes, Ex/Em $490 / 516 \mathrm{~nm}$ ), which selectively stains mitochondria both in live cells and in cells that have been fixed. Then sections were mounted on adhesive (Vecta Bond) coated glass slides, with a DNA dye, 4',6 diamidino-2-phenylindole (DAPI), containing mounting medium (Vectashield, Vector Laboratories) in order to evaluate mitochondrial mass in cells with nuclear counterstaining in blue (Ex/Em 359/461 nm). The mitochondrial free radicals were analyzed by monitoring the oxidized fluorescence product (Ex/Em 554/576 nm) of CM-H2XRos under a fluorescence microscope. Integrated optical density (IOD), number of mitochondria, and its mitochondrial area were determined by using image analysis software (Image-Pro Plus v5.0). Results are presented here as a CMH2XRos/MitGreen IODs quotient.

2.5. Mitochondrial Isolation. For mitochondrial isolation, briefly, brain tissue was minced and placed in prechilled Dounce homogenizer with SHE buffer $(0.25 \mathrm{M}$ sucrose, $5 \mathrm{mM}$ HEPES and $1 \mathrm{mM}$ EGTA,. PH 7.4), followed by centrifugation at 2,500 $\mathrm{rpm}$ for $10 \mathrm{~min}, 4^{\circ} \mathrm{C}$, and recentrifugation of the supernatant $(8,500 \mathrm{rpm}, 10 \mathrm{~min})$, to obtain a crude mitochondrial pellet. Following a $10 \mathrm{~min}$ incubation in ice, the pellet was resuspended again in SHE plus delipidized bovine serum albumin (Sigma Chemical Company). Albumin was eliminated by centrifugating this suspension of mitochondria at 9,500 rpm for $10 \mathrm{~min}$. The protein content in the mitochondrial fraction was determined by Lowry's method [49].

2.6. Fluidity Changes of Mitochondrial Membranes. 1,3 dipyrenylpropane (DPP) incorporation into membranes to form intramolecular excimers depends mainly on medium microviscosity and temperature of determination (24). Membrane fluidity is determined by estimating the excimer to monomer fluorescence intensity ratio ( $\mathrm{Ie} / \mathrm{Im}$ ) of this fluorescent probe, a quotient that reflects lateral mobility of membrane phospholipids (25). Briefly, mitochondria were resuspended in Tris- $\mathrm{HCl}$ buffer $(50 \mathrm{mM}, \mathrm{pH} 8)$ and then fragmented by sonication for 15 seconds before being separated by centrifugation at 13,000 rpm. The mitochondrial membrane pellet was resuspended and proteins were measured by Lowry's method. $0.1 \mathrm{mg}$ of mitochondrial protein was mixed in a spectrofluorometric cell containing Tris- $\mathrm{HCl}(20 \mathrm{mM}$, $\mathrm{pH}$ 7.5). DPP solution in ethanol of spectroscopic grade was diluted $(0.02 \mathrm{mg} / \mathrm{mL})$ and mixed with membranes given a molar ratio of fluorescent probe to membrane phospholipids of $1: 1400$; these mixtures were incubated in darkness for 4 hours at room temperature. Fluorescence of $\mathrm{DPP}$ incorporated into membranes was measured at $24^{\circ} \mathrm{C}$ on a Perkin Elmer fluorescence spectrometer, LS50B. The fluorophore was excited at $329 \mathrm{~nm}$ and the monomer and excimer fluorescence intensities were read at 379 and $480 \mathrm{~nm}$, respectively.

2.7. Chromatographic Analysis of Fatty Acids. Fatty acids from membranes were extracted with chloroform:methanol $(2: 1 \mathrm{vol} / \mathrm{vol})$ and analyzed by gas-liquid chromatography. Briefly, C17:0 heptadecanoic acid, as internal standard, was added to $1 \mathrm{mg}$ of mitochondrial protein and the mixture of methanol and chloroform, both dissolved in BHT, was added. After centrifugation, the chloroform phase was extracted and a second extraction was done by adding anhydrous sodium sulphate. The extract was evaporated under nitrogen, reacted with a mix of methanol, sulfuric acid, and toluene at $90^{\circ} \mathrm{C}$ for 2 hours, and then redissolved in hexane and a $5 \%$ saline solution. Following the extraction of the organic phase, the hexane was evaporated under nitrogen to obtain derivatized fatty acids to be placed into the injector of a Carlo Erba gas chromatograph with flame ionization detection; the temperature of the injector was $250^{\circ} \mathrm{C}$ and the oven temperature was maintained at $196^{\circ} \mathrm{C}$, using helium as a carrier gas at $1.4 \mathrm{~kg} / \mathrm{cm}^{2}$.

2.8. Chromatographic Anaylsis of Phospholipids. Phospholipids were extracted with a methanol/chloroform solution mixed in a 2:1 ratio, dried in a SpeedVac, and then redissolved in chloroform. Following a second extraction adding anhydrous sodium sulphate, the solution was filtrated and then evaporated. Samples were analyzed by highpressure liquid chromatography. Results are provided in relative percentage from the correspondent areas in the chromatogram.

2.9. Chromatographic Anaylsis of Cholesterol. Membrane lipids were extracted with chloroform:methanol $(2: 1 \mathrm{vol} /$ vol) and analyzed by gas-liquid chromatography. Briefly, $10 \mu \mathrm{g}$ of stigmasterol, as internal standard, was added to $1 \mathrm{mg}$ of mitochondrial protein and the mixture of methanol and chloroform, both dissolved in BHT, was added. Extracted lipids react for 1 hour at $60^{\circ} \mathrm{C}$ with a mix of hexamethyldisilazane, trimethyl fluorosilane, and dry pyridine to convert free cholesterol and stigmasterol in their corresponding trimethyl esters. The mixture was evaporated with nitrogen and then redissolved in hexane to be injected into the Carlo Erba gas chromatograph with flame ionization detection; the temperature of the injector was set to $275^{\circ} \mathrm{C}$, the temperature of the detector was $260^{\circ} \mathrm{C}$, and that of the oven 
was maintained at $275^{\circ} \mathrm{C}$. Helium was used as a carrier gas at $1.5 \mathrm{~kg} / \mathrm{cm}^{2}$.

2.10. Statistical Analysis. All data are shown as means $\pm \mathrm{SE}$ of triplicate experiments. Statistical analysis of the data for multiple comparisons was performed by two-way ANOVA followed by Student's tests. For a single comparison, the significance of any differences between means was determined by unpaired $t$-tests. The criterion for significance was $P<$ 0.05 in all statistical evaluations.

\section{Results}

3.1. A $\beta$ at the Brain Enters the Neurons and Eventually Presents in Mitochondrial Membranes. 12, 24, 36 and 48 hours following the intracerebral injection of fibrillar $\mathrm{A} \beta$, deposits of $\mathrm{A} \beta$ forming aggregates were reactive to $\mathrm{A} \beta$ polyclonal antibody and revealed by immunohistochemistry. Congophilic amyloid deposits remained visible up to 21 days following the intracerebral injection (data not shown). Tissue sections of $50 \mu \mathrm{m}$, obtained with a vibratome, were used for immunoelectron microscopy and the $\mathrm{A} \beta$ positive immunoreactions were observed in mitochondria along the membranes and deep in the cristae. The presence of $\mathrm{A} \beta$ deposits in mitochondria was accompanied by a significant lost of their architecture, characterized by swelling, broken cristae, lost of membrane integrity, and vacuole formation (Figure 1).

3.2. The Lost of the Cytoarchitecture Was Related to Free Radical Overproduction. CM-H2XROS is a reduced, non fluorescent X-rosamine derivative, which is sequestered by mitochondria where it is retained and oxidized. Under oxidation, CM-H2XROS emits fluorescence as a consequence of the number of free radicals produced by mitochondria. This reagent is normally used in in vitro experiments after adding it to cells in culture. To demonstrate the effects of $\mathrm{A} \beta$ in vivo, we have introduced a variant by injecting CM-H2XROS intraperitoneally 15 minutes before tissue collections (as explained). Once the tissue was obtained, sections of the lesioned area were immediately cut in a vibratome and stained with Mito Tracker Green (MitGreen), which is essentially nonfluorescent in aqueous solutions, only becoming fluorescent once it accumulates within the lipid environment of the mitochondrion. Thus, the CM$\mathrm{H} 2 \mathrm{XROS} / \mathrm{MitGreen} \mathrm{IOD} \mathrm{quotient} \mathrm{identifies} \mathrm{the} \mathrm{quantity} \mathrm{of}$ free radicals by the mitochondria present on each field of the microscope. We found a significant overproduction of free radicals both in $\mathrm{A} \beta$ - and in $\mathrm{H}_{2} \mathrm{O}_{2}$-treated brains $(P<0.05)$ as compared to PBS-injected brains. Brains of animals who had received melatonin showed significantly lower levels of free radicals $(P<0.05)$ (Figure 2$)$.

3.3. Membrane Fluidity Was Inversely Correlated to Free Radical Overproduction. The highest value in membrane fluidity was observed in PBS-injected brains, which showed the lowest amount of free radicals as well (Figure 3). The highest overproduction of free radicals, according to the CM$\mathrm{H} 2 \mathrm{XROS} / \mathrm{MitGreen}$ IOD quotient, was observed in $\mathrm{H}_{2} \mathrm{O}_{2}$ injected brains. Interestingly, even though the production of free radicals in brains injected with $\mathrm{fA} \beta$ was significantly higher than the quantity of free radicals observed in the PBS group, the difference between membrane fluidity and free radical overproduction was less obvious, as compared with the positive control group of $\mathrm{H}_{2} \mathrm{O}_{2}$. Brains of animals treated with melatonin had significantly reduced levels of free radicals and the difference between these and membrane fluidity was again obvious (Figure 3 ).

3.4. The Unsaturated/Saturated Ratio, Significantly Affected by $A \beta$, Is Restored by Melatonin. A $\beta$ increased palmitic (16:0) and estearic (18:0) saturated fatty acids, 39 and $37 \%(P<$ $0.05)$, correspondingly. Additionally, $\mathrm{A} \beta$ reduced linoleic acid $(18: 2)$ at less than $35 \%$ the observed value in the PBS-injected brains $(P<0.05)$ and decreased linolenic acid $(18: 3)$ value $80 \%$ below the observed value in the PBS-injected brains. Additionally, A $\beta$ significantly increased the polyunsaturated arachidonic acid $(20: 4)(P<0.05$, from $29.4 \pm 2$ to $51 \pm 2.5)$. Thus, the elevated increase in saturated plus the severe decrement in linoleic and linolenic acids (Figure 4) was mostly responsible for an alteration in the ratio of unsaturated to saturated fatty acids in membrane phospholipids which is critical to normal cellular function.

The lower unsaturated to saturated ratio was observed in $\mathrm{fA} \beta$-injected brains to be even lower than the positive control group of $\mathrm{H}_{2} \mathrm{O}_{2}, \mathrm{fA} \beta$ and $\mathrm{H}_{2} \mathrm{O}_{2}$ being the groups of study where the overproduction of free radicals was significant (Figure 2). With the use of melatonin, the U/S ratio returned significantly closer to control values (Figure 5), which reflected melatonin's role on each particular fatty acid (Figure 4).

However, the aforementioned showed that a drastic reduction in linolenic acid, a precursor of arachidonic acid $(20: 4, \mathrm{n} 6)$, and in linoleic acid, a precursor of docosohexanoic acid $(22: 6, n 3)$, was reflected in the $A \beta$-induced levels of $\mathrm{AA}$ and DHA levels (Figure 6). In the $\mathrm{A} \beta$-injected brains, arachidonic acid rose $20 \%$ in relation to the PBSinjected control values $(P<0.05)$, while DHA levels showed approximately $30 \%$ increase value $(P<0.05)$. This similar increment in both variables allows that the relationship between these relative values or DHA/AA ratio remains stable in $\mathrm{A} \beta$-injected brains as compared to PBS-injected brains (Figure 6).

Except for the palmitic acid and the arachidonic acid, the rest of the $A \beta$-altered fatty acids tend to return to their basal levels, similar to PBS levels, when the animals were treated with melatonin (fA $\beta+$ Mel group), as shown in Figures 46. Another exception was the N3, 20:5, polyunsaturated eicosapentaenoic fatty acid (EPA) which seemed to be unaffected by $\mathrm{A} \beta$ (Figure 7). However, the EPA-to-AA ratio showed a significant reduction $(P<0.05)$. Interestingly, in $\mathrm{A} \beta$-injected brains from melatonin-treated animals, EPA values were $60 \%$ and $43 \%$ higher than those observed in PBSand in $\mathrm{A} \beta$-injected brains. As a result, the EPA to AA ratio was restored (Figure 7). 


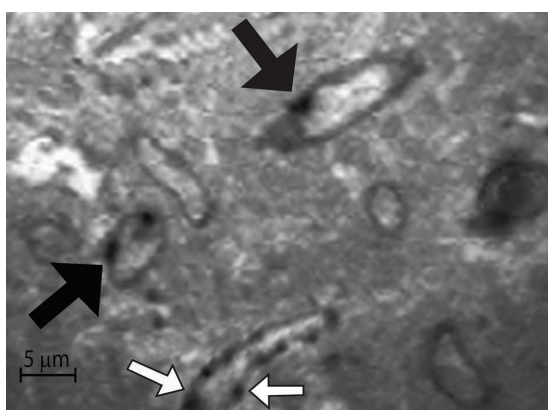

(a)

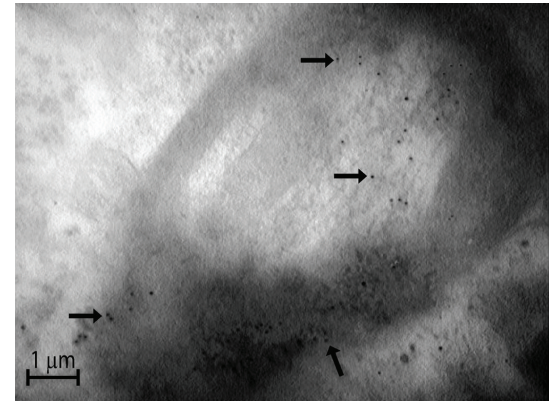

(b)

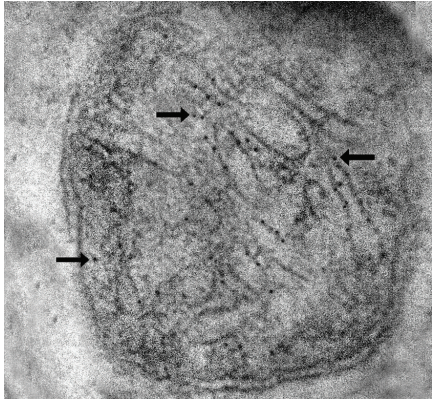

(c)

FIgURE 1: A $\beta$ stain by immunoelectron microscopy. 36 hours after the intracerebral injection of $A \beta$ tissues from the injected area were obtained and subjected to immunohistochemistry by using a primary polyclonal antibody against $\mathrm{A} \beta$. Deposits of $\mathrm{A} \beta$ forming deposits in the extracellular space were revealed by conventional light microscopy (data not shown). A $\beta$ immunoreactivity was then revealed with a $6 \mathrm{~nm}$ gold label and observed in a transmission electron microscope which allows us to identify (a) deposits of A $\beta$ within myelin axons (black arrows) and in the vasculature (white arrows). (b) Deposits of $A \beta$ (black arrows) penetrate the axon membranes causing demyelination and appear in the axons. Axons look like bulb onions. (c) A $\beta$ appears within the mitochondria finally, where it forms deposits along the cristae (black arrows) and causes intense inflammation, destruction of membranes, and vacuolization (magnification at 27800x).

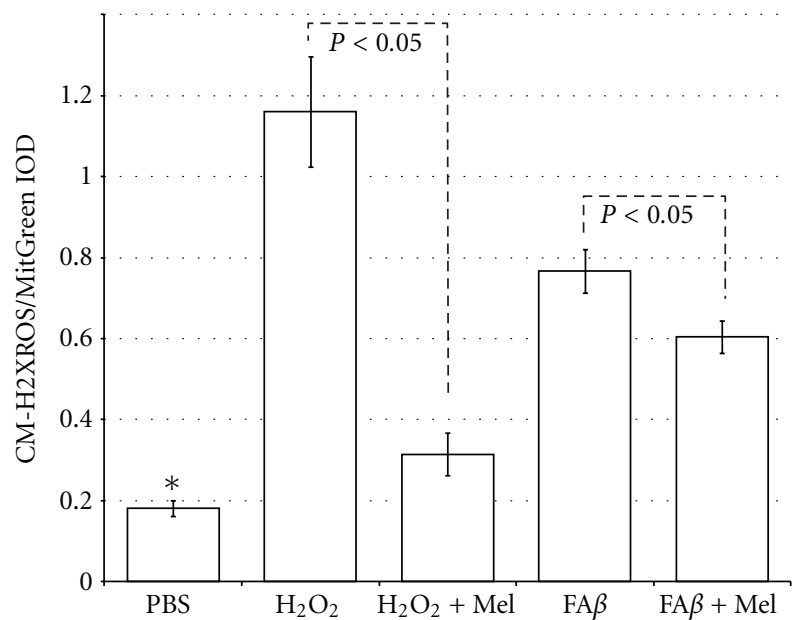

FIGURE 2: Compared with PBS-injected brains, those brains injected with $\mathrm{A} \beta$ or with $\mathrm{H}_{2} \mathrm{O}_{2}$ had a significant increase in free radical levels in mitochondria, according to the CM-H2XROS/MitGreen quotient ( ${ }^{*} P<0.05$ versus all the other groups). However, by using melatonin a significant decrease in mitochondrial free radicals was observed both in $\mathrm{A} \beta$ - and in $\mathrm{H}_{2} \mathrm{O}_{2}$-injected brains.

3.5. A $\beta$ Induced Significant Alterations in Mitochondrial Membrane Phospholipids. Thus, while the effect of phosphatidyl ethanolamine (PtdEA) levels was reduced by a third in the fA $\beta$ group $(P<0.05)$, levels of phosphatidyl choline (PtdCHOL) were increased 40\% $(P<0.05)$, but the phosphatidyl serine (PtdSER) values reached $120 \%$ as compared to PBS-injected brains (Figure 8). On the contrary, brains of animals treated with melatonin showed PtdEA levels similar to PBS-injected brains, while levels of PtdSER were significantly reduced with melatonin even beyond the control values $(P<0.05)$. PtdCHOL levels were also significantly reduced in presence of melatonin (Figure 8 ).

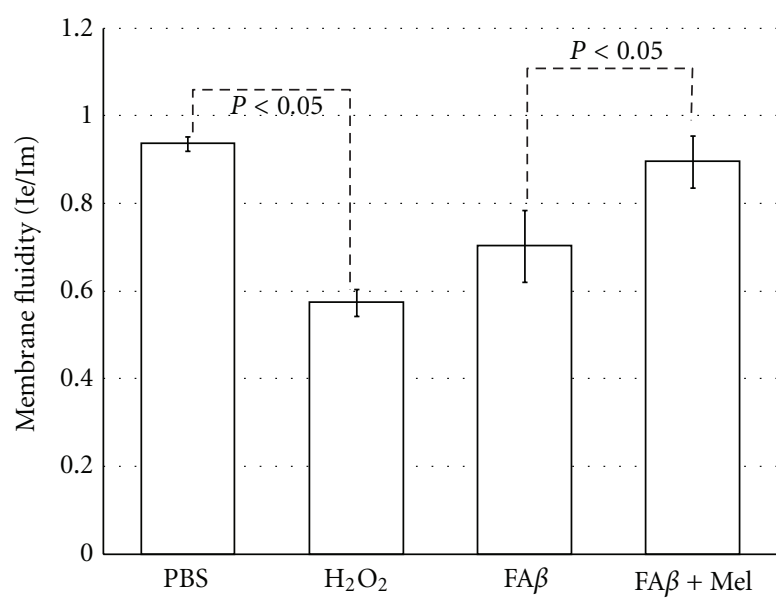

FIGURE 3: Brains of animals injected with $\mathrm{A} \beta$ showed a significant reduction in membrane fluidity as compared with PBS-injected brains, although less obvious than the observed in $\mathrm{H}_{2} \mathrm{O}_{2}$-injected brains, used as a positive control, which is in concordance with the degree of the free radicals overproduction, as shown in the previous graphic. Membrane fluidity in animals receiving melatonin was restored at the same level than the PBS group.

3.6. Variations in Cholesterol Content Follow the Same Pattern As Variations in Free Radicals. The lowest cholesterol values were found in the PBS-injected brains and the highest values were observed in the $\mathrm{H}_{2} \mathrm{O}_{2}$-injected brains $(P<0.05)$. The concentration of cholesterol in fA $\beta$-injected brains was significantly higher $(59.6 \pm 5.7$ versus $47.6 \pm 5.2 \mu \mathrm{g} / \mathrm{mg}$ of protein, $P<0.05)$ than that in the control brains treated with PBS; this value was only $66 \%$ the value in $\mathrm{H}_{2} \mathrm{O}_{2}$-injected brains ( $59.6 \pm 5.7$ versus $90.24 \pm 11$, data not shown). In spite of the significant increase in the membrane fluidity observed in $\mathrm{fA} \beta+\mathrm{Mel}$ brains, this change was apparently not related to the cholesterol content since melatonin did not change the levels of cholesterol in $\mathrm{fA} \beta$-injected brains ( $\mathrm{fA} \beta 60 \pm 6$ versus 


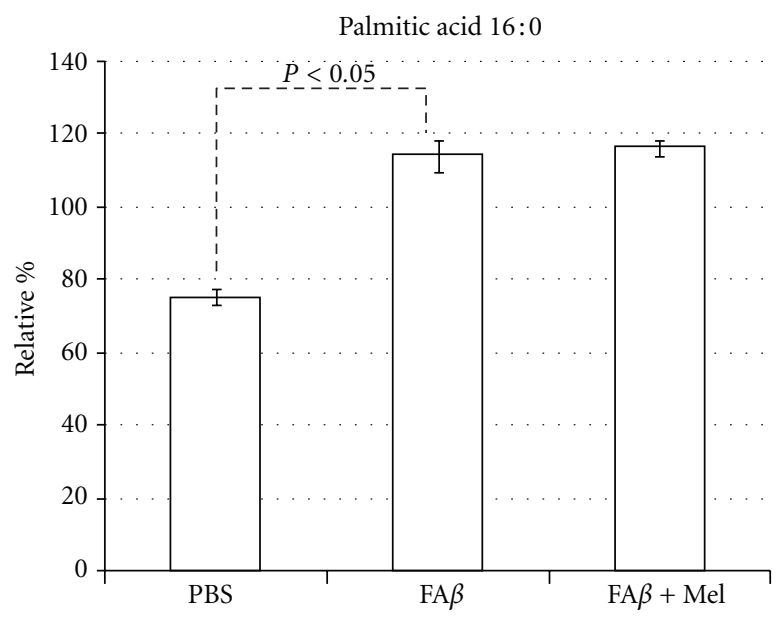

(a)

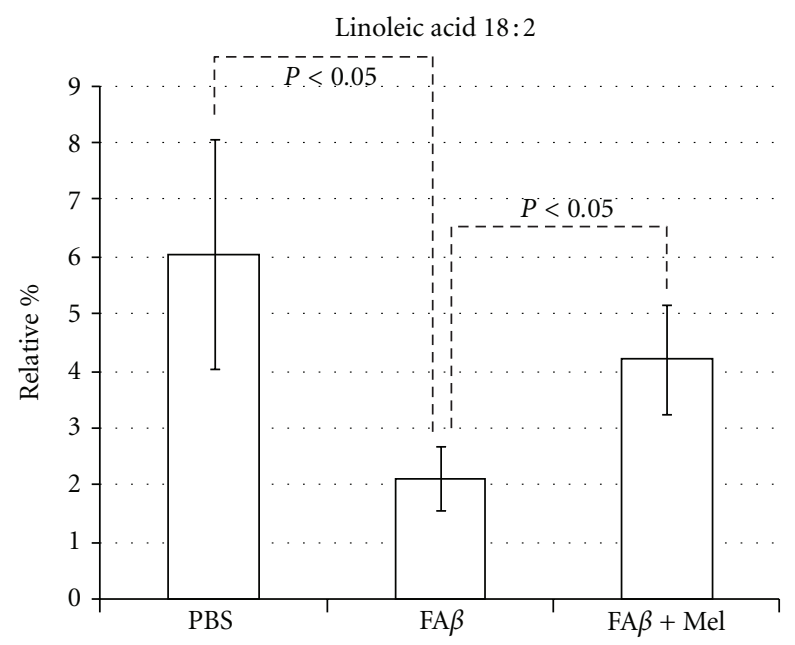

(c)

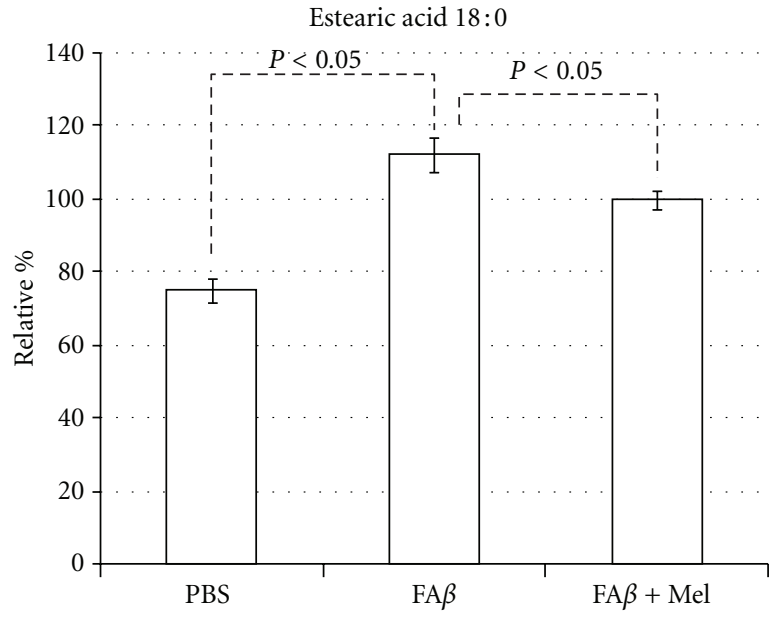

(b)

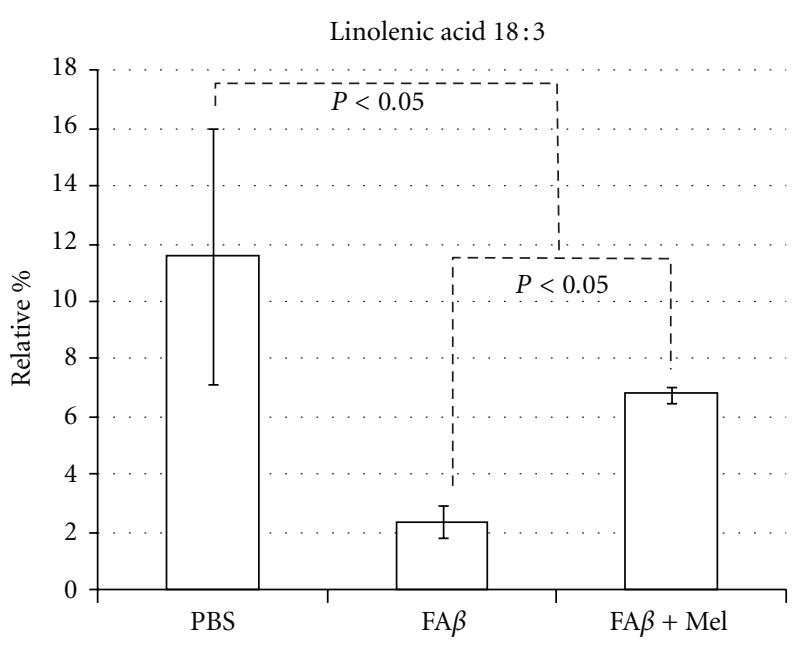

(d)

FIgURE 4: $\mathrm{A} \beta$ and $\mathrm{H}_{2} \mathrm{O}_{2}$ (not shown) had similar and highly significant effects on saturated fatty acids particularly on palmitic and estearic acids whose percentages were increased 39 and $37 \%$ correspondingly. Linoleic acid was reduced to a third from the control, while linolenic acid was reduced to less than a quart from the control value, as shown. These important effects of $\mathrm{A} \beta$ on specific saturated and unsaturated fatty acids affected the unsaturated/saturated (U/S) balance.

fA $\beta+$ Mel $61 \pm 7$ ) (Figure 9). The cholesterol-to-phospholipid ratio, on the other side, which reflects a loss of phospholipid and membrane rigidity, was significantly altered by $\mathrm{A} \beta$, with the inability of melatonin to return it to the level found in PBS-injected brains (Figure 9).

\section{Discussion}

Lipid and fatty acid changes have been studied in plasma membranes, especially in both postmortem $\mathrm{AD}$ brain and transgenic mice. These changes have been associated with aging, $\mathrm{A} \beta$ deposits, dementia, and even mild cognitive impairment. Other experiments have been carried out in vitro by using purified synaptosomal plasma or mitochondrial membranes. To our knowledge, no studies have focused on mitochondrial membranes in response to in vivo extracellular deposits of fibrillar $A \beta$. In spite of its known ability to induce oxidative stress, alterations in lipid content of mitochondrial membranes induced by extracellular $A \beta$ differed from those induced by $\mathrm{H}_{2} \mathrm{O}_{2}$.

Mitochondrial dysfunction has been related to oxidative stress in neurodegeneration as both cause and effect. At the same time, there is increasing evidence for membrane lipid, fatty acid, and cholesterol interactions with $\mathrm{A} \beta$. These interactions have significant consequences in the pathogenesis of Alzheimer's disease. Our original aim was to demonstrate that extracellular deposits of $\mathrm{A} \beta$, in vivo, would be able to induce mitochondrial failure as well as changes in mitochondrial lipid composition as a consequence of its ability to induce oxidative stress. $\mathrm{H}_{2} \mathrm{O}_{2}$ was chosen as positive control since endogenous hydrogen peroxide has been indicated as a secondary messenger mediating the intracellular effects of $A \beta$ extracellular deposits. Furthermore, a relationship between 


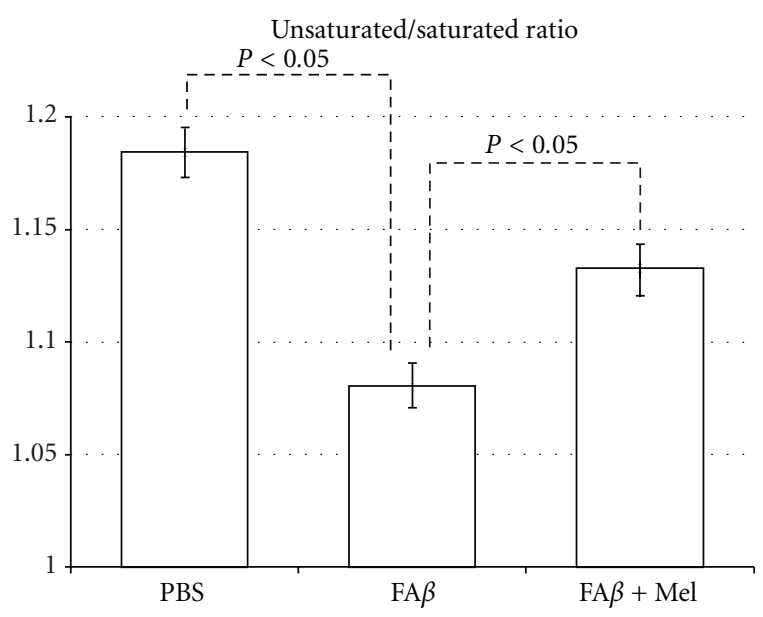

FIGURE 5: fA $\beta$-injected brains decreased significantly the U/S ratio, as compared with the PBS-injected brains. However, brains of animals taking oral melatonin showed a U/S ratio closer to the control group.

the accumulation of $\mathrm{A} \beta$ monomers and oligomers and $\mathrm{H}_{2} \mathrm{O}_{2}$ production in the mitochondria of $\mathrm{Tg} 2576$ mice has been reported. However, we found that important $\mathrm{A} \beta$-induced alterations were significantly different from those induced by $\mathrm{H}_{2} \mathrm{O}_{2}$. AA levels, for example, were significantly higher in the fA $\beta$ group than those in the $\mathrm{H}_{2} \mathrm{O}_{2}$ group $(P<0.05)$. The ratio U/S was not affected by $\mathrm{H}_{2} \mathrm{O}_{2}$, basically due to minimal effects on or to compensations between decrements and increments in one or another group of saturated versus unsaturated fatty acids. $\mathrm{A} \beta$, increasing saturated fatty acids and decreasing unsaturated fatty acids, caused a persistent and significant decrement of the U/S ratio (Figure 5). This finding agrees with another work where the ability of $A \beta$ to interfere with the $\Delta-9$ desaturase enzyme was observed. $\Delta-9$ desaturase introduces the first double bond between carbon 9 and 10 of palmitoyl (16:0) or stearyl (18:0) Co A to form palmitoleic $(16: 1)$ or oleic $(18: 1)$ acids [19].

This profound fatty acid imbalance was reflected in phospholipid levels, in such a manner that $\mathrm{H}_{2} \mathrm{O}_{2}$ did not affect the levels of PtdEA, but $A \beta$ reduced significantly this phospholipid. However, the most severe effect of $A \beta$ was observed in PtdSER, causing a 5-fold increment, whereas $\mathrm{H}_{2} \mathrm{O}_{2}$ did not affect this parameter.

There seems to be a different mechanism of damage. While the strict oxidative damage, represented by our positive control group $\mathrm{H}_{2} \mathrm{O}_{2}$, caused the highest increment in PtdEA levels, $\mathrm{A} \beta$ reduced PtdEA levels and, on the contrary, increased very significantly the PtdSER levels and, less important but also significantly, the PtdCHOL levels (Figure 10).

Thus, $A \beta$ deleterious effects were not oxidative stress related-or at least not completely explained by oxidative alterations-which is evident when comparing the differing effects of $\mathrm{H}_{2} \mathrm{O}_{2}$ and $\mathrm{A} \beta$ on membrane lipids $(P<0.05)$. Fatty acid (FA) composition of phospholipids determines biophysical (and functional) characteristics of membranes (e.g., membrane fluidity) and plays an important role in cellular integrity and intra- and intercellular communication. We found a significant $(P<0.001)$ inverse correlation $\left(r^{2}=-0.74\right)$ between mitochondrial membrane fluidity and cholesterol content. Indeed, we found that $\mathrm{A} \beta$ and $\mathrm{H}_{2} \mathrm{O}_{2}$ caused the more severe oxidative stress, the lowest membrane fluidity, and the highest cholesterol content. However, in the $A \beta$ group the reduction of oxidative stress seemed not to affect the cholesterol increment, although $A \beta$ had a more severe effect on fatty acids (Figures 5, 6, and 7) and phospholipid redistribution (Figure 10).

A tendency of cholesterol to aggregate into clusters at a cholesterol/phospholipid ratio of greater than 0.3 is known since 1972 [50], and we have found a $0.3 \pm .08$ cholesterol to phospholipid ratio in $\mathrm{fA} \beta$-injected brains due principally to a severe decrement in PtdEA against an increment in cholesterol content (Figures 8 and 9). Cholesterol aggregates in membranes are a well-known characteristic of $\mathrm{A} \beta$ induced damage $[30,51,52]$. High-cholesterol diet has been associated with increased deposits of $\mathrm{A} \beta$ [53], and we have found [54] that animals fed with a cholesterol-enriched diet presented a significant increase in mitochondrial structural damage linked to severe dysfunction of this organelle. It was noticeable that, according to our results, melatonin could not impair this cholesterol re-arrangement but was able to induce a significant increment in membrane fluidity (Figure 3). This phenomenon illustrates the role of lipid peroxidation and the reaccommodation of phospolipids, particularly PtdSer and PtdEA, along the membranes as determinants of membrane fluidity, beyond the role of cholesterol [55].

$\mathrm{A} \beta_{42}$ oligomers accumulate more slowly and in reduced amount at the plasma membranes of fibroblasts from familial $\mathrm{AD}$ (FAD) patients enriched in cholesterol [56]. On the other side, it is also reported that $\mathrm{A} \beta$ binds lipids, but with a higher affinity for cholesterol than PtdCHOL or saturated fatty acids [51]. We may therefore speculate, according to our results, that the cholesterol rearrangement observed in brain cells may be a defensive response against oxidative stress, with a secondary effect, $\mathrm{A} \beta$ binding.

Specific alterations in fatty acids have been related to $\mathrm{A} \beta$ pathogenesis. For example, unsaturated fatty acids oleic acid, and linoleic acid, have been shown to increase the $\gamma$ secretase activity and $\mathrm{A} \beta$ levels, as evaluated in PSwt- 1 cells, which contains the wild-type human presenilin 1 (PS1) and wild-type human APP full-length cDNAs, [11]. According to our results, $A \beta$ decreased severely the content of linoleic acid $(6.5 \mathrm{~mol} \%$ in PBS-injected brains versus $2.12 \mathrm{~mol} \%$ in A $\beta$-injected brains, $P<0.05$ ), as observed in old Wistar rat brain, which implies that this effect occurs regardless of the ApoE phenotype.

The importance of the ApoE phenotype involves the carrying of proteins in combination with lipids to form lipoprotein particles with hydrophobic lipids at the core and hydrophilic side chains made of amino acids. ApoE also aids the transport of triglyceride, phospholipid, and cholesterol into cells, by mediating the binding, internalization, and catabolism of lipoprotein particles [57]. ApoE is considered a risk factor in $\mathrm{AD}$ because $40-65 \%$ of $\mathrm{AD}$ patients have at least one copy of the 4 alleles; although the exact mechanism 


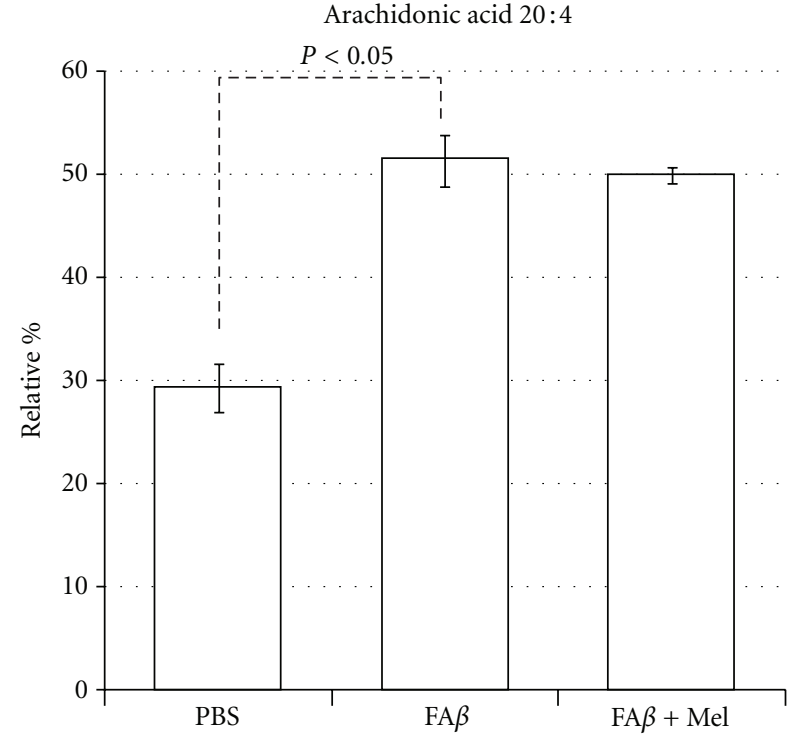

(a)

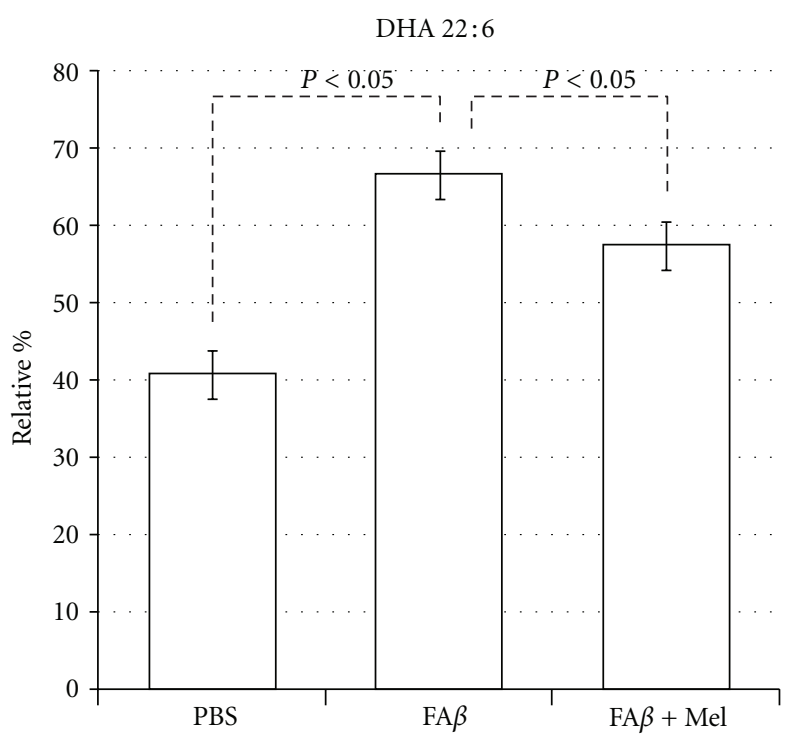

(b)

DHA/AA

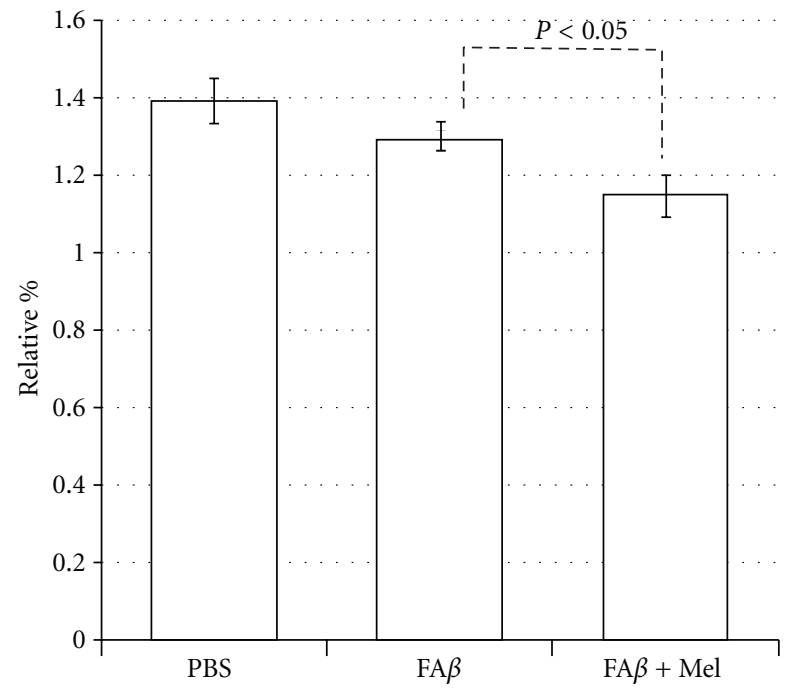

(c)

FIgURE 6: $\mathrm{A} \beta$ and $\mathrm{H}_{2} \mathrm{O}_{2}$ (not shown) produced important increases in both $\mathrm{n} 6$ and $\mathrm{n} 3 \mathrm{PUFA}$, which reflects the previous described changes in free fatty acids. A similar increase in DHA and AA allowed the DHA/AA ratio to remain stable, when compared with the PBS group. It is obvious that melatonin reduces the DHA/AA ratio, particularly at the expense of a decrease in DHA levels.

of this feature remains to be fully determined, an interaction with amyloid insoluble protein aggregates or with APP seems to be involved $[58,59]$. How ApoE controls brain lipids and how this regulation may impact the clearance of $A \beta$ or the progression of damage are less clear [60]. In postmortem brain samples, no significant difference in lipids or fatty acids was found between $\mathrm{AD}$ patients classified as homozygous for ApoE4 and those classified as heterozygous or having no ApoE4 [10, 61]. Thus, ApoE genotype on fatty acids and lipid composition and/or its distribution in brain cell membranes seem to have no significance and would not bias our results. Additionally, by comparing the association of human, rat, and rabbit $A p o E$ with $A \beta$, a similar lack of affinity for $A \beta$ between rat ApoE and human ApoE4 has been reported [62]. Thus, rat ApoE, the same as the AD-related ApoE4, does not form complex with $A \beta$.

Another fatty acid whose relationship with $\mathrm{A} \beta$ pathogeny has been widely studied is AA. This N6 PUFA is an agonist of proinflammatory pathways, which additionally as has been reported increase the levels of $A \beta$ [63]. It is known also that $\mathrm{A} \beta$ oligomers trigger neuronal apoptosis by early activation of a cPLA2-dependent pathway leading to production of AA [14]. We found that the AA precursor linoleic acid was reduced while $\mathrm{AA}$ was increased by $\mathrm{A} \beta$, which supports the 
EPA 20:5

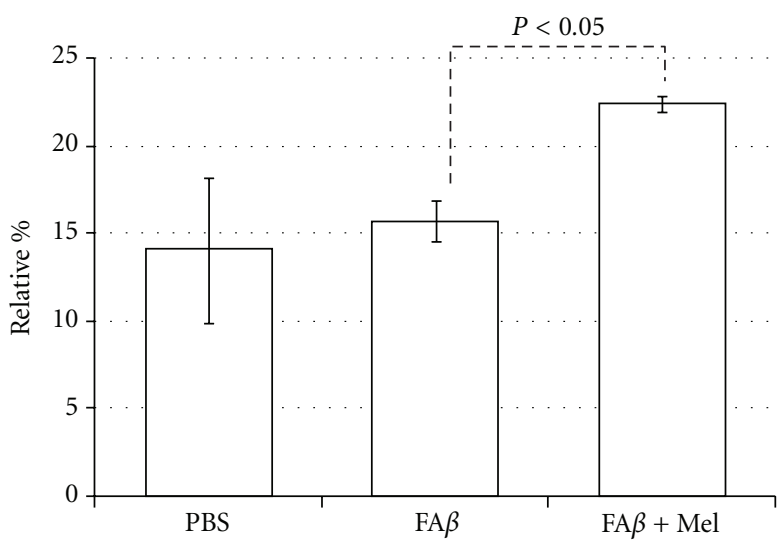

(a)

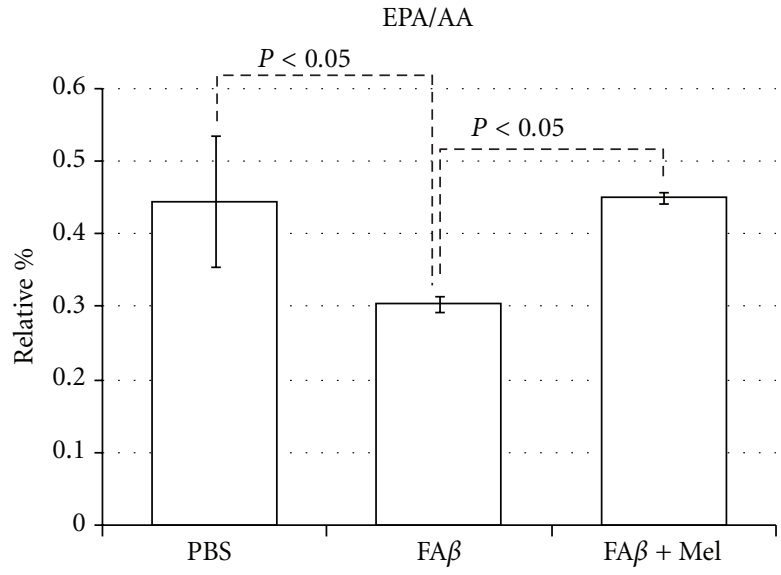

(b)

FIGURE 7: EPA was not to significantly responsive to $\mathrm{A} \beta$. However, in the presence of melatonin and contrary to the results with the other major n3 PUFA, DHA, the relative percentage of EPA rose significantly, which impacted the EPA/AA ratio, as shown.

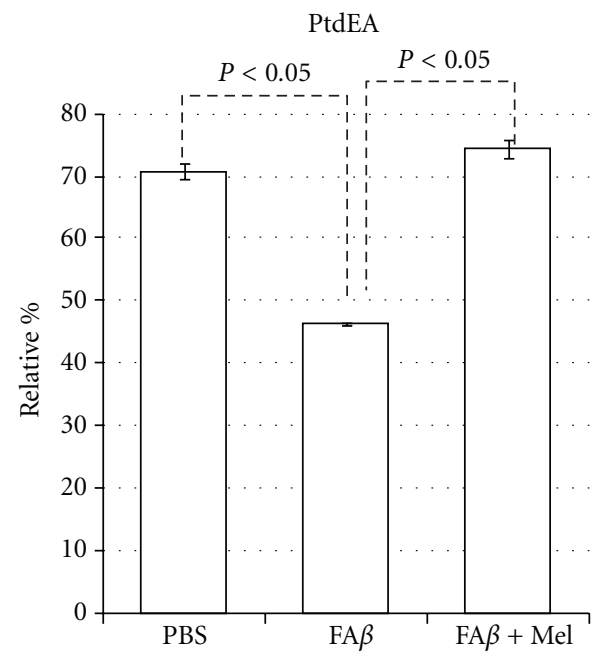

(a)

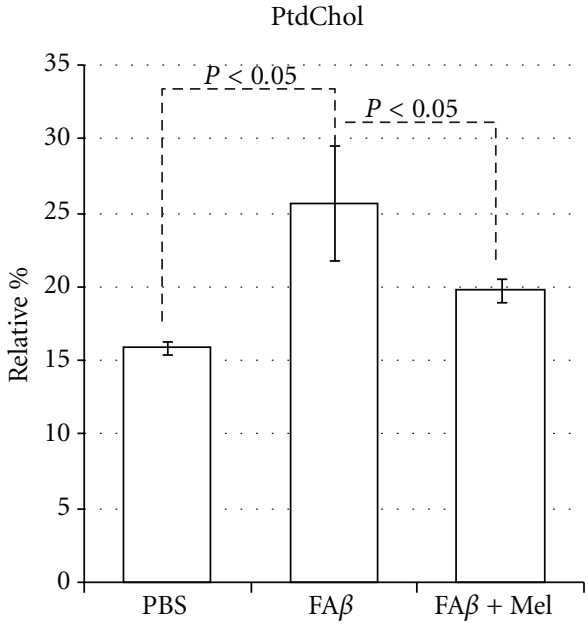

(b)

PtdSER

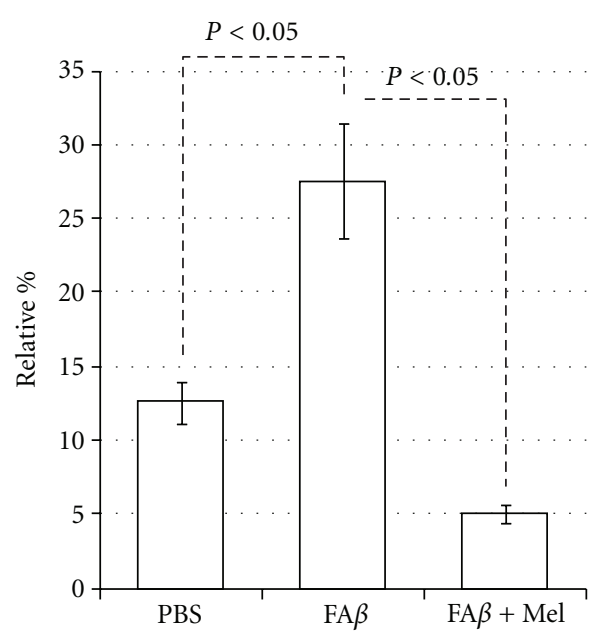

(c)

Figure 8: A $\beta$ decreased significantly the PtdEA levels and increased the levels of PtdCHOL and PtdSER, the latter with a 5-fold increment. Results are expressed in relative percentage \pm standard error. 


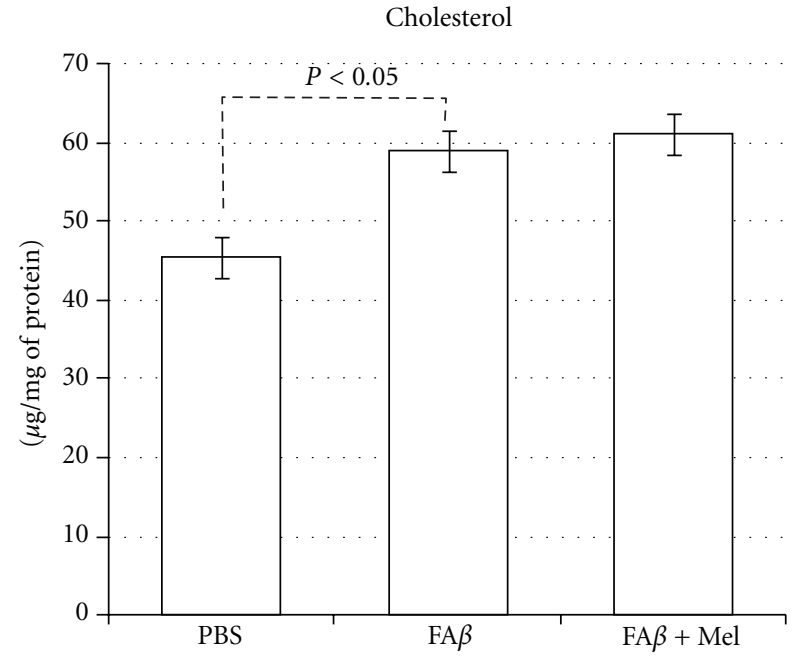

(a)

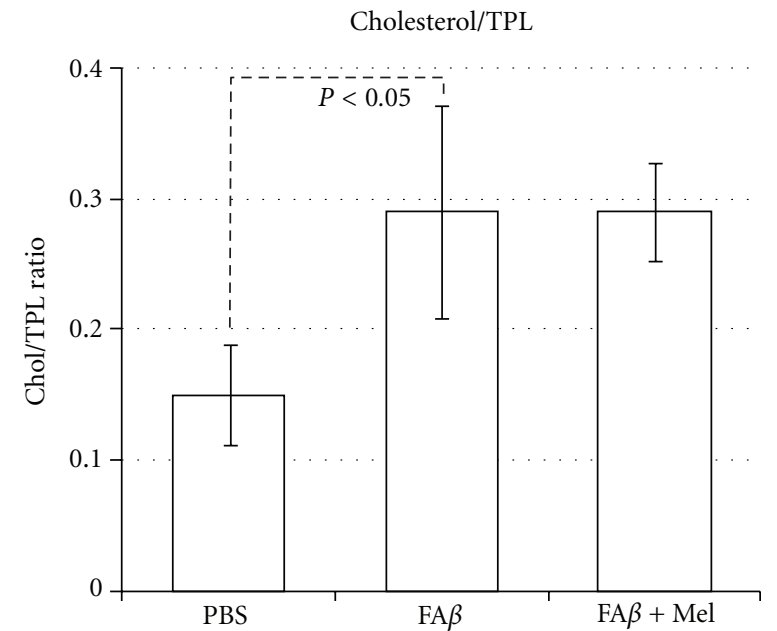

(b)

FIGURE 9: Cholesterol content in mitochondrial membranes is significantly increased in fA $\beta$ injected brains. The $\mathrm{H}_{2} \mathrm{O}_{2}$ control group (data not shown) and the fA $\beta$ experimental group, which showed the more important overproduction of free radicals and the lowest membrane fluidity, coincide with the highest cholesterol content. However, in spite of its ability to scavenge free radicals and restore membrane fluidity, melatonin was unable to reduce cholesterol content in mitochondrial membrane. Compared according to their relative values, cholesterol and total phospholipids ratio was significantly altered.

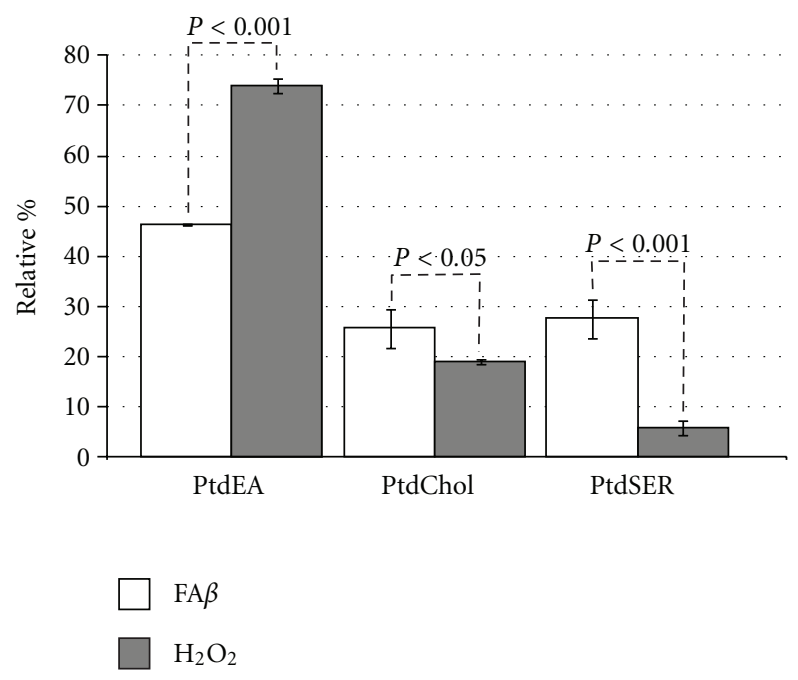

Figure 10: Significant differences between $\mathrm{A} \beta$-injected brains and $\mathrm{H}_{2} \mathrm{O}_{2}$-injected brains.

proposal that $\mathrm{A} \beta$ paves its own way by changing the quality and distribution of lipid membranes.

Herein we report important alterations in mitochondrial membranes following the intracerebral injection of $A \beta$. There is important in this context the relationship between n6 and n3 PUFA, particularly the relationship between the proinflammatory AA with its counterparts DHA and EPA. EPA and DHA differ in their effects on plasma lipid profiles, gene expression, and neural membrane structure. EPA downregulates the enzymes involved in DHA synthesis and decreases DHA synthesis from its precursor, $\alpha$-linolenic acid [64]. We have found that $A \beta$ increased both DHA and $\mathrm{AA}$, while the levels of EPA remained stable, but the treatment with melatonin, which did not affect the levels of AA, was able to increase very importantly EPA. EPA has been reported as anti-inflammatory upon several conditions and different cell types, but importantly in aging and $A \beta$ induced neuroinflammation [65-67]. Specifically EPA is linked to a modulatory role in microglial activity [68]. We have reported a remarkable reduction in microglial activity in rats intracerebrally injected with $\mathrm{A} \beta$ but under melatonin treatment [4].

Even though being examined in a different context, there is a report where melatonin was found protective of AA, DHA, and EPA. Arachidonic acid was protected more efficiently than DHA and EPA at all the melatonin concentrations examined when rat liver microsomes were incubated with ascorbic acid [69], which is quite similar to our results (Figures 6 and 7). This phenomenon is linked to protection against lipid peroxidation, a remarkable ability of melatonin supported by its amphoteric nature as well as its ability to cross the blood-brain barrier (BBB) and enter into the central nervous system [70].

Evaluated in cortical synaptosomes from gerbils, a loss of phospholipid asymmetry induced by $\mathrm{A} \beta_{1-42}$ has been reported [71]. This phenomenon implies the oxidative modification of the flippase enzyme by reactive alkenals which causes externalization of PtdSER and the subsequent phospholipid asymmetry, which in turn causes membrane dysfunction, $\mathrm{Ca}^{++}$massive influx, and apoptosis. The anionic PtdSER also may increase the fibrillization of $\mathrm{A} \beta$ [72]. We found that $\mathrm{A} \beta$ causes a $120 \%$ increase in PtdSER levels. However PtdSER levels in brains of animals which received melatonin treatment decreased 5 times compared to brains from animals without melatonin treatment. 


\section{Conclusions}

The relationship between membrane lipids with $A \beta$ is usually focused on how lipids may allow, facilitate, or even induce the amyloidogenic processing of APP. This relationship is also explored to explain how $\mathrm{A} \beta$ causes cellular dysfunction.

Our approach to the in vivo study of the $\mathrm{A} \beta_{1-42}$ peptide, the predominantly neurotoxic form of $A \beta$, was to inject the peptide directly into the hippocampus and then examine the relationship with membrane lipids, in order to explain how $A \beta$ may penetrate the cell and then approach to mitochondria and cause the well-known severe dysfunction of this organelle.

The intracellular amyloid cascade is, of course, widely studied and elegantly explained [73-75]. It is also likely that the pathogenically critical process of $A \beta$ oligomerization may begin intraneuronally and the energy hypometabolism may appear before the presence of senile plaques or neurofibrillary tangles [76]. However, without discarding the previous statements, there is evidence to consider the extracellular $\mathrm{A} \beta$ as the principal source of intracellular $\mathrm{A} \beta$, given the huge amounts of $A \beta$ in aggregates, the physical properties of this peptide, and its ability to alter fatty acids and lipids on membranes, either because of its pro-oxidant activity or because of its physical interactions with lipids.

We reported how exogenous $A \beta$ forms deposits in the extracellular space, then presents inside the cellsparticularly through the axons causing demyelination, which agrees with other reports $[5,6]$ —and, finally, how $A \beta$ is found inside mitochondria where it causes severe structural damage linked to free radical overproduction and significant alterations in mitochondrial membrane lipids.

By using melatonin, it is possible to ameliorate the membrane fluidity without affecting cholesterol content in membranes, while it restores the balance of lipids. Importantly, melatonin reduces the negatively charged PtdSER in membranes and, by this means, might impair the toxicity of $\mathrm{A} \beta$. Another important feature is how melatonin may increase EPA content in membranes, restoring the EPA/AA ratio, a phenomenon widely known by its anti-inflammatory effects. Melatonin restores membrane structure and functionality, an effect which exclusively could not be attributed to its antioxidant capacity.

\section{Acknowledgment}

The authors appreciate the facilities given to them by Dr. Mohammed El Hafidi Bentlakder, from the Department of Biochemistry of the Instituto Nacional de Cardiología Ignacio Chávez, México City.

\section{References}

[1] D. De Pietri Tonelli, M. Mihailovich, A. Di Cesare, F. Codazzi, F. Grohovaz, and D. Zacchetti, "Translational regulation of BACE-1 expression in neuronal and non-neuronal cells," Nucleic Acids Research, vol. 32, no. 5, pp. 1808-1817, 2004.
[2] J. E. Maggio and P. W. Mantyh, "Brain amyloid-a physicochemical perspective," Brain Pathology, vol. 6, no. 2, pp. 147$162,1996$.

[3] S. M. Yatin, S. Varadarajan, C. D. Link, and D. A. Butterfield, "In vitro and in vivo oxidative stress associated with Alzheimer's amyloid $\beta$-peptide (1-42)," Neurobiology of Aging, vol. 20, no. 3, pp. 325-342, 1999.

[4] S. Rosales-Corral, D. X. Tan, R. J. Reiter et al., "Orally administered melatonin reduces oxidative stress and proinflammatory cytokines induced by amyloid- $\beta$ peptide in rat brain: a comparative, in vivo study versus vitamin C and E," Journal of Pineal Research, vol. 35, no. 2, pp. 80-84, 2003.

[5] H. Lassmann, "Mechanisms of neurodegeneration shared between multiple sclerosis and Alzheimer's disease," Journal of Neural Transmission, vol. 118, no. 5, pp. 747-752, 2011.

[6] S. Mitew, M. T. K. Kirkcaldie, G. M. Halliday, C. E. Shepherd, J. C. Vickers, and T. C. Dickson, "Focal demyelination in Alzheimer's disease and transgenic mouse models," Acta Neuropathologica, vol. 119, no. 5, pp. 567-577, 2010.

[7] M. S. Brown, J. Ye, R. B. Rawson, and J. L. Goldstein, "Regulated intramembrane proteolysis: a control mechanism conserved from bacteria to humans," Cell, vol. 100, no. 4, pp. 391-398, 2000.

[8] S. Patil, L. Sheng, A. Masserang, and C. Chan, "Palmitic acidtreated astrocytes induce BACE1 upregulation and accumulation of C-terminal fragment of APP in primary cortical neurons," Neuroscience Letters, vol. 406, no. 1-2, pp. 55-59, 2006.

[9] S. Patil and C. Chan, "Palmitic and stearic fatty acids induce Alzheimer-like hyperphosphorylation of tau in primary rat cortical neurons," Neuroscience Letters, vol. 384, no. 3, pp. 288293, 2005.

[10] M. Igarashi, K. Ma, F. Gao, H. W. Kim, S. I. Rapoport, and J. S. Rao, "Disturbed choline plasmalogen and phospholipid fatty acid concentrations in Alzheimer's disease prefrontal cortex," Journal of Alzheimer's Disease, vol. 24, no. 3, pp. 507-517, 2011.

[11] Y. Liu, L. Yang, K. Conde-Knape, D. Beher, M. S. Shearman, and N. S. Shachter, "Fatty acids increase presenilin-1 levels and $\gamma$-secretase activity in PSwt-1 cells," Journal of Lipid Research, vol. 45, no. 12, pp. 2368-2376, 2004.

[12] M. A. Lovell, C. Xie, and W. R. Markesbery, "Decreased glutathione transferase activity in brain and ventricular fluid in Alzheimer's disease," Neurology, vol. 51, no. 6, pp. 15621566, 1998.

[13] H. Esterbauer, R. J. Schaur, and H. Zollner, "Chemistry and Biochemistry of 4-hydroxynonenal, malonaldehyde and related aldehydes," Free Radical Biology and Medicine, vol. 11, no. 1, pp. 81-128, 1991.

[14] B. Kriem, I. Sponne, A. Fifre et al., "Cytosolic phospholipase A2 mediates neuronal apoptosis induced by soluble oligomers of the amyloid- $\beta$ peptide," The FASEB Journal, vol. 19, no. 1, pp. 85-87, 2005.

[15] G. P. Lim, F. Calon, T. Morihara et al., "A diet enriched with the omega-3 fatty acid docosahexaenoic acid reduces amyloid burden in an aged Alzheimer mouse model," Journal of Neuroscience, vol. 25, no. 12, pp. 3032-3040, 2005.

[16] C. Sahlin, F. E. Pettersson, L. N. G. Nilsson, L. Lannfelt, and A. S. Johansson, "Docosahexaenoic acid stimulates nonamyloidogenic APP processing resulting in reduced A $\beta$ levels in cellular models of Alzheimer's disease," European Journal of Neuroscience, vol. 26, no. 4, pp. 882-889, 2007.

[17] M. Umezawa, K. Kogishi, H. Tojo et al., "High-linoleate and high- $\alpha$-linolenate diets affect learning ability and natural 
behavior in SAMR1 mice," Journal of Nutrition, vol. 129, no. 2, pp. 431-437, 1999.

[18] N. G. Bazan, "Synaptic signaling by lipids in the life and death of neurons," Molecular Neurobiology, vol. 31, no. 1-3, pp. 219230, 2005.

[19] J. E. Morley, S. A. Farr, V. B. Kumar, and W. A. Banks, "Alzheimer's disease through the eye of a mouse: acceptance lecture for the 2001 Gayle A. Olson and Richard D. Olson prize," Peptides, vol. 23, no. 3, pp. 589-599, 2002.

[20] J. McLaurin and A. Chakrabartty, "Characterization of the interactions of Alzheimer $\beta$-amyloid peptides with phospholipid membranes," European Journal of Biochemistry, vol. 245, no. 2, pp. 355-363, 1997.

[21] E. Terzi, G. Holzemann, and J. Seelig, "Self-association of $\beta$-amyloid peptide (1-40) in solution and binding to lipid membranes," Journal of Molecular Biology, vol. 252, no. 5, pp. 633-642, 1995.

[22] O. Simakova and N. J. Arispe, "The cell-selective neurotoxicity of the Alzheimer's A $\beta$ peptide is determined by surface phosphatidylserine and cytosolic ATP levels. Membrane binding is required for A $\beta$ toxicity," Journal of Neuroscience, vol. 27, no. 50, pp. 13719-13729, 2007.

[23] M. B. Hampton, D. M. Vanags, M. I. Pörn-Ares, and S. Orrenius, "Involvement of extracellular calcium in phosphatidylserine exposure during apoptosis," FEBS Letters, vol. 399, no. 3, pp. 277-282, 1996.

[24] S. A. Rosales-Corral, D. Acuna-Castroviejo, A. Coto-Montes et al., "Alzheimer's disease: pathological mechanisms and the beneficial role of melatonin," Journal of Pineal Research, vol. 52, no. 2, pp. 167-202, 2012.

[25] G. Lee, H. B. Pollard, and N. Arispe, "Annexin 5 and apolipoprotein E2 protect against Alzheimer's amyloid- $\beta$ peptide cytotoxicity by competitive inhibition at a common phosphatidylserine interaction site," Peptides, vol. 23, no. 7, pp. 1249-1263, 2002.

[26] Z. Lai, W. Colón, and J. W. Kelly, "The acid-mediated denaturation pathway of transthyretin yields a conformational intermediate that can self-assemble into amyloid," Biochemistry, vol. 35, no. 20, pp. 6470-6482, 1996.

[27] M. R. R. de Planque, V. Raussens, S. A. Contera et al., "BetaSheet structured beta-amyloid(1-40) perturbs phosphatidylcholine model membranes," Journal of Molecular Biology, vol. 368, no. 4, pp. 982-997, 2007.

[28] G. P. Eckert, C. Kirsch, S. Leutz, W. G. Wood, and W. E. Müller, "Cholesterol modulates amyloid beta-peptide's membrane interactions," Pharmacopsychiatry, vol. 36, supplement 2, pp. S136-S143, 2003.

[29] W. Gibson Wood, G. P. Eckert, U. Igbavboa, and W. E. Muller, "Amyloid beta-protein interactions with membranes and cholesterol: causes or casualties of Alzheimer's disease," Biochim Biophys Acta, vol. 1610, no. 2, pp. 281-290, 2003.

[30] A. Kakio, S. I. Nishimoto, K. Yanagisawa, Y. Kozutsumi, and K. Matsuzaki, "Cholesterol-dependent formation of GM1 ganglioside-bound amyloid beta-protein, an endogenous seed for Alzheimer amyloid," The Journal of Biological Chemistry, vol. 276, no. 27, pp. 24985-24990, 2001.

[31] S. Subasinghe, S. Unabia, C. J. Barrow, S. S. Mok, M. I. Aguilar, and D. H. Small, "Cholesterol is necessary both for the toxic effect of $\mathrm{A} \beta$ peptides on vascular smooth muscle cells and for $\mathrm{A} \beta$ binding to vascular smooth muscle cell membranes," Journal of Neurochemistry, vol. 84, no. 3, pp. 471-479, 2003.

[32] A. Buchsteiner, T. Hauss, S. Dante, and N. A. Dencher, "Alzheimer's disease amyloid-beta peptide analogue alters the ps-dynamics of phospholipid membranes," Biochim Biophys Acta, vol. 1798, no. 10, pp. 1969-1976, 2010.

[33] L. Qiu, C. Buie, A. Reay, M. W. Vaughn, and K. H. Cheng, "Molecular dynamics simulations reveal the protective role of cholesterol in beta-amyloid protein-induced membrane disruptions in neuronal membrane mimics," Journal of Physical Chemistry B, vol. 115, no. 32, pp. 9795-9812, 2011.

[34] G. D’Errico, G. Vitiello, O. Ortona, A. Tedeschi, A. Ramunno, and A. M. D'Ursi, "Interaction between Alzheimer's Abeta(2535) peptide and phospholipid bilayers: the role of cholesterol," Biochim Biophys Acta, vol. 1778, no. 12, pp. 2710-2716, 2008.

[35] P. Mecocci, A. Cherubini, M. F. Beal et al., "Altered mitochondrial membrane fluidity in AD brain," Neuroscience Letters, vol. 207, no. 2, pp. 129-132, 1996.

[36] J. J. Chen and B. P. Yu, "Alterations in mitochondrial membrane fluidity by lipid peroxidation products," Free Radical Biology and Medicine, vol. 17, no. 5, pp. 411-418, 1994.

[37] P. Leaden, J. Barrionuevo, and A. Catalá, "The protection of long chain polyunsaturated fatty acids by melatonin during nonenzymatic lipid peroxidation of rat liver microsomes," Journal of Pineal Research, vol. 32, no. 3, pp. 129-134, 2002.

[38] Z. Feng, C. Qin, Y. Chang, and J. T. Zhang, "Early melatonin supplementation alleviates oxidative stress in a transgenic mouse model of Alzheimer's disease," Free Radical Biology and Medicine, vol. 40, no. 1, pp. 101-109, 2006.

[39] M. Gavazza and A. Catalá, "Melatonin preserves arachidonic and docosapentaenoic acids during ascorbate- $\mathrm{Fe}^{2+}$ peroxidation of rat testis microsomes and mitochondria," International Journal of Biochemistry and Cell Biology, vol. 35, no. 3, pp. 359$366,2003$.

[40] K. Hensley, J. M. Carney, M. P. Mattson et al., "A model for $\beta$ amyloid aggregation and neurotoxicity based on free radical generation by the peptide: relevance to Alzheimer disease," Proceedings of the National Academy of Sciences of the United States of America, vol. 91, no. 8, pp. 3270-3274, 1994.

[41] J. J. Liang, C. L. Gu, M. L. Kacher, and C. S. Foote, "Chemistry of singlet oxygen. 45. Mechanism of the photooxidation of sulfides," Journal of the American Chemical Society, vol. 105, no. 14, pp. 4717-4721, 1983.

[42] N. G. N. Milton, "Role of hydrogen peroxide in the aetiology of Alzheimer's disease: implications for treatment," Drugs and Aging, vol. 21, no. 2, pp. 81-100, 2004.

[43] C. Behl, J. B. Davis, R. Lesley, and D. Schubert, "Hydrogen peroxide mediates amyloid $\beta$ protein toxicity," Cell, vol. 77, no. 6, pp. 817-827, 1994.

[44] C. Shi, F. Wu, and J. Xu, "H2O2 and PAF mediate $\mathrm{A} \beta 1-$ 42 -induced $\mathrm{Ca}^{2+}$ dyshomeostasis that is blocked by EGb761," Neurochemistry International, vol. 56, no. 8, pp. 893-905, 2010.

[45] M. Manczak, T. S. Anekonda, E. Henson, B. S. Park, J. Quinn, and P. H. Reddy, "Mitochondria are a direct site of $\mathrm{A} \beta$ accumulation in Alzheimer's disease neurons: implications for free radical generation and oxidative damage in disease progression," Human Molecular Genetics, vol. 15, no. 9, pp. 1437-1449, 2006.

[46] D. T. Weldon, S. D. Rogers, J. R. Ghilardi et al., "Fibrillar $\beta$-amyloid induces microglial phagocytosis, expression of inducible nitric oxide synthase, and loss of a select population of neurons in the rat CNS in vivo," Journal of Neuroscience, vol. 18, no. 6, pp. 2161-2173, 1998.

[47] K. Ishii, F. Muelhauser, U. Liebl et al., "Subacute NO generation induced by Alzheimer's $\beta$-amyloid in the living brain: reversal by inhibition of the inducible NO synthase," The FASEB Journal, vol. 14, no. 11, pp. 1485-1489, 2000. 
[48] G. Paxinos, The Rat Nervous System, Academic Press, Sydney, Australia, 1984.

[49] O. H. Lowry, N. J. Rosebrough, A. L. Farr, and R. J. Randall, "Protein measurement with the Folin phenol reagent," The Journal of Biological Chemistry, vol. 193, no. 1, pp. 265-275, 1951.

[50] D. M. Engelman and J. E. Rothman, "The planar organization of lecithin-cholesterol bilayers," The Journal of Biological Chemistry, vol. 247, no. 11, pp. 3694-3697, 1972.

[51] N. A. Avdulov, S. V. Chochina, U. Igbavboa, C. S. Warden, A. V. Vassiliev, and W. G. Wood, "Lipid binding to amyloid $\beta$-peptide aggregates: preferential binding of cholesterol as compared with phosphatidylcholine and fatty acids," Journal of Neurochemistry, vol. 69, no. 4, pp. 1746-1752, 1997.

[52] A. Kakio, S. Nishimoto, Y. Kozutsumi, and K. Matsuzaki, "Formation of a membrane-active form of amyloid betaprotein in raft-like model membranes," Biochemical and Biophysical Research Communications, vol. 303, no. 2, pp. 514$518,2003$.

[53] L. Ginsberg, J. H. Xuereb, and N. L. Gershfeld, "Membrane instability, plasmalogen content, and Alzheimer's disease," Journal of Neurochemistry, vol. 70, no. 6, pp. 2533-2538, 1998.

[54] S. A. Rosales-Corral, D. Acuna-Castroviejo, D.-X. Tan et al., "Alzheimer's disease: pathological mechanisms and the beneficial role of melatonin," Journal Pineal Research, vol. 52, no. 2, pp. 167-202, 2012.

[55] M. Shinitzky and Y. Barenholz, "Fluidity parameters of lipid regions determined by fluorescence polarization," Biochimica et Biophysica Acta, vol. 515, no. 4, pp. 367-394, 1978.

[56] A. Pensalfini, M. Zampagni, G. Liguri et al., "Membrane cholesterol enrichment prevents $\mathrm{A} \beta$-induced oxidative stress in Alzheimer's fibroblasts," Neurobiology of Aging, vol. 32, no. 2, pp. 210-222, 2011.

[57] J. E. Eichner, S. T. Dunn, G. Perveen, D. M. Thompson, K. E. Stewart, and B. C. Stroehla, "Apolipoprotein E polymorphism and cardiovascular disease: a HuGE review," American Journal of Epidemiology, vol. 155, no. 6, pp. 487-495, 2002.

[58] M. J. Sadowski, J. Pankiewicz, H. Scholtzova et al., "Blocking the apolipoprotein E/amyloid- $\beta$ interaction as a potential therapeutic approach for Alzheimer's disease," Proceedings of the National Academy of Sciences of the United States of America, vol. 103, no. 49, pp. 18787-18792, 2006.

[59] S. Haß, F. Fresser, S. Köchl, K. Beyreuther, G. Utermann, and G. Baier, "Physical interaction of ApoE with amyloid precursor protein independent of the amyloid $\mathrm{A} \beta$ region in vitro," The Journal of Biological Chemistry, vol. 273, no. 22, pp. 13892 13897, 1998.

[60] S. Arold, P. Sullivan, T. Bilousova et al., "Apolipoprotein E level and cholesterol are associated with reduced synaptic amyloid beta in Alzheimer's disease and apoE TR mouse cortex," Acta Neuropathologica, vol. 123, no. 1, pp. 39-52, 2012.

[61] T. Fraser, H. Tayler, and S. Love, "Fatty acid composition of frontal, temporal and parietal neocortex in the normal human brain and in Alzheimer's disease," Neurochemical Research, vol. 35, no. 3, pp. 503-513, 2010.

[62] M. J. LaDu, J. R. Lukens, C. A. Reardon, and G. S. Getz, "Association of human, rat, and rabbit apolipoprotein E with beta-amyloid," Journal of Neuroscience Research, vol. 49, no. 1, pp. 9-18, 1997.

[63] Z. Amtul, M. Uhrig, and K. Beyreuther, "Additive effects of fatty acid mixtures on the levels and ratio of amyloid $\beta 40 / 42$ peptides differ from the effects of individual fatty acids," Journal of Neuroscience Research, vol. 89, no. 11, pp. 17951801, 2011.
[64] B. Langelier, J. M. Alessandri, M. H. Perruchot, P. Guesnet, and M. Lavialle, "Changes of the transcriptional and fatty acid profiles in response to n-3 fatty acids in SH-SY5Y neuroblastoma cells," Lipids, vol. 40, no. 7, Article ID L9735, pp. 719-728, 2005.

[65] T. Babcock, W. S. Helton, and N. J. Espat, "Eicosapentaenoic acid (EPA): an antiinflammatory $\omega-3$ fat with potential clinical applications," Nutrition, vol. 16, no. 11-12, pp. 1116-1118, 2000.

[66] A. M. Lynch, D. J. Loane, A. M. Minogue et al., "Eicosapentaenoic acid confers neuroprotection in the amyloid- $\beta$ challenged aged hippocampus," Neurobiology of Aging, vol. 28, no. 6, pp. 845-855, 2007.

[67] A. M. Minogue, A. M. Lynch, D. J. Loane, C. E. Herron, and M. A. Lynch, "Modulation of amyloid- $\beta$-induced and ageassociated changes in rat hippocampus by eicosapentaenoic acid," Journal of Neurochemistry, vol. 103, no. 3, pp. 914-926, 2007.

[68] A. Bernardo, G. Levi, and L. Minghetti, "Role of the peroxisome proliferator-activated receptor- $\gamma$ (PPAR- $\gamma$ ) and its natural ligand 15-deoxy- $\Delta(12,14)$-prostaglandin $\mathrm{J} 2$ in the regulation of microglial functions," European Journal of Neuroscience, vol. 12, no. 7, pp. 2215-2223, 2000.

[69] P. L. Tang, M. F. Xu, and Z. M. Qian, "Differential behaviour of cell membranes towards iron-induced oxidative damage and the effects of melatonin," Biological Signals, vol. 6, no. 4-6, pp. 291-300, 1997.

[70] R. J. Reiter, J. Cabrera, R. M. Sainz, J. C. Mayo, L. C. Manchester, and D. X. Tan, "Melatonin as a pharmacological agent against neuronal loss in experimental models of Huntington's disease, Alzheimer's disease and Parkinsonism," Annals of the New York Academy of Sciences, vol. 890, pp. 471-485, 1999.

[71] H. M. Abdul and D. A. Butterfield, "Protection against amyloid beta-peptide (1-42)-induced loss of phospholipid asymmetry in synaptosomal membranes by tricyclodecan-9xanthogenate (D609) and ferulic acid ethyl ester: implications for Alzheimer's disease," Biochimica et Biophysica Acta, vol. 1741, no. 1-2, pp. 140-148, 2005.

[72] A. Chauhan, I. Ray, and V. P. S. Chauhan, "Interaction of amyloid beta-protein with anionic phospholipids: possible involvement of Lys 28 and C-terminus aliphatic amino acids," Neurochemical Research, vol. 25, no. 3, pp. 423-429, 2000.

[73] A. J. Yang, D. Chandswangbhuvana, T. Shu, A. Henschen, and C. G. Glabe, "Intracellular accumulation of insoluble, newly synthesized $A \beta n-42$ in amyloid precursor protein-transfected cells that have been treated with A $\beta 1-42$," The Journal of Biological Chemistry, vol. 274, no. 29, pp. 20650-20656, 1999.

[74] C. A. Hansson Petersen, N. Alikhani, H. Behbahani et al., "The amyloid $\beta$-peptide is imported into mitochondria via the TOM import machinery and localized to mitochondrial cristae," Proceedings of the National Academy of Sciences of the United States of America, vol. 105, no. 35, pp. 13145-13150, 2008.

[75] R. H. Swerdlow and S. M. Khan, "The Alzheimer's disease mitochondrial cascade hypothesis: an update," Experimental Neurology, vol. 218, no. 2, pp. 308-315, 2009.

[76] H. Atamna and W. H. Frey, "Mechanisms of mitochondrial dysfunction and energy deficiency in Alzheimer's disease," Mitochondrion, vol. 7, no. 5, pp. 297-310, 2007. 


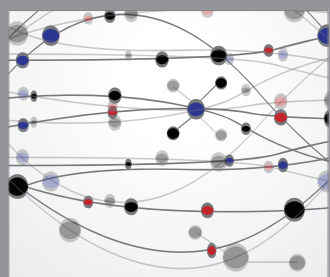

The Scientific World Journal
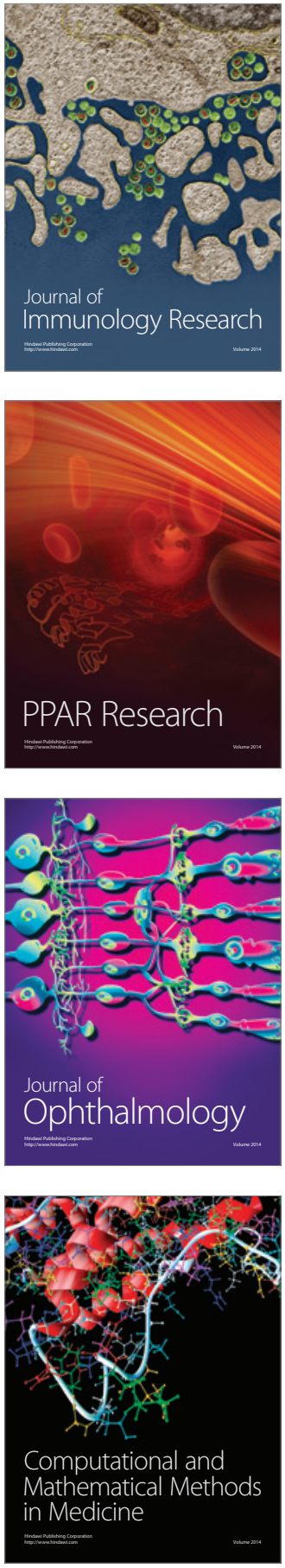

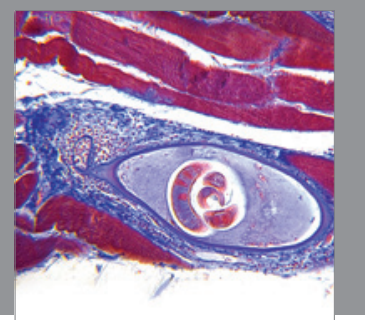

Gastroenterology

Research and Practice
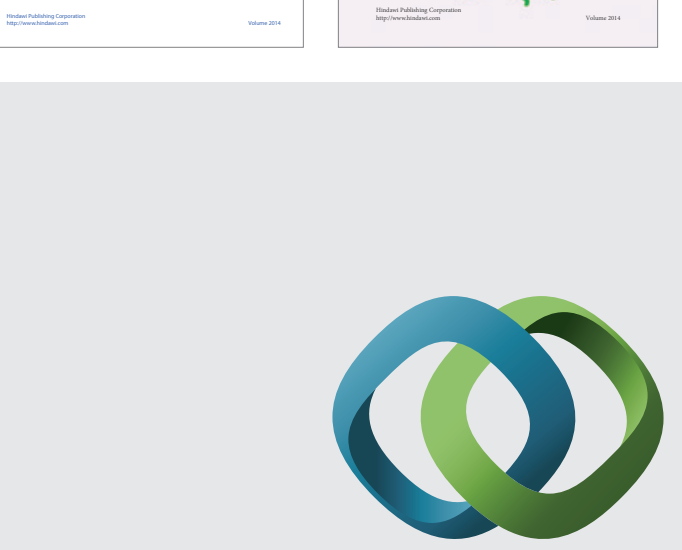

\section{Hindawi}

Submit your manuscripts at

http://www.hindawi.com
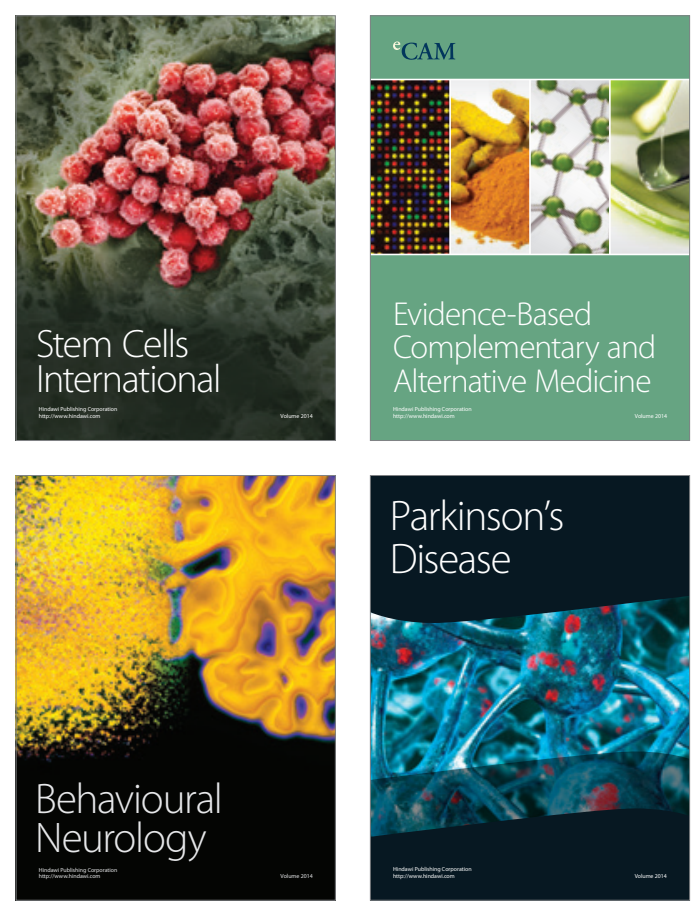

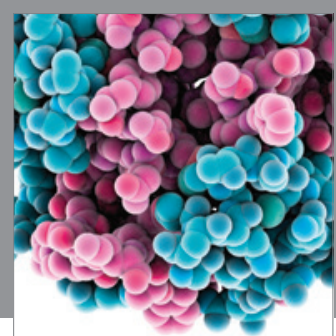

Journal of
Diabetes Research

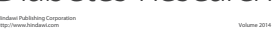

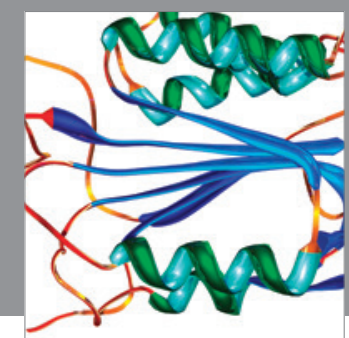

Disease Markers
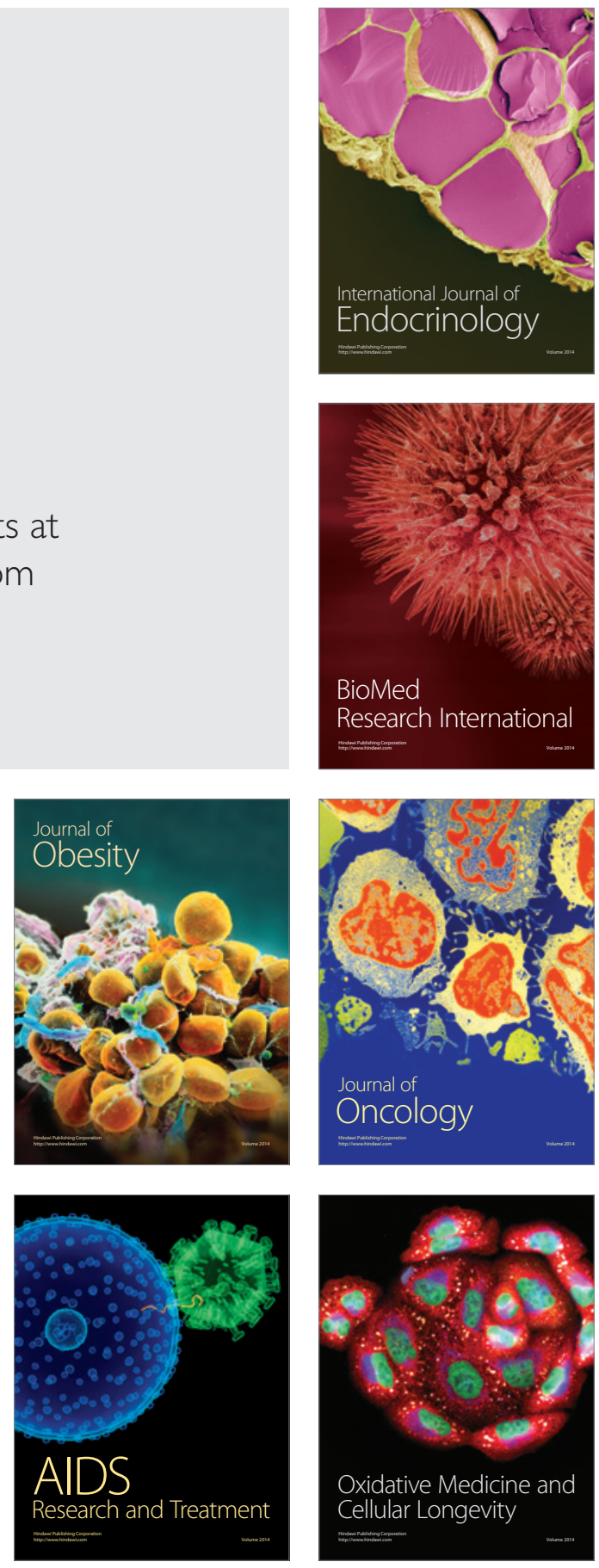